\title{
Estimation of the perforation force for polymer composite conveyor belts taking into consideration the shape of the piercing punch
}

\author{
Dominik Wojtkowiak $^{1} \cdot$ Krzysztof Talaśka $^{1} \cdot$ Ireneusz Malujda ${ }^{1} \cdot$ Grzegorz Domek $^{2}$
}

Received: 16 February 2018 / Accepted: 27 June 2018 / Published online: 13 July 2018

(C) The Author(s) 2018

\begin{abstract}
Due to the improvement of the mechanical properties of polymer composite belts used in vacuum belt conveyors, its perforation process causes a lot of technical issues for manufacturers worldwide. The objective of this paper is to analyze the belt punching process with two cutting edges and present the influence of the piercing punch shape on the perforation force. Based on the analysis, the analytical stress model was derived and validated by using both empirical and FEM tests. The application of the proposed model was proved by presenting the methodology used to estimate the perforation force for the flat piercing punch based on the mechanical properties of the belt obtained from simple strength tests (uniaxial tension, compression, and shear), with an error between 4 and 15\%. In this report, the analysis of the piercing punch profiles was made and eight different piercing punch profiles were tested. Presented results confirmed that the spherical bowl punch may be considered as a most effective tool for belt punching, because it reduced the perforation force by $60 \%$ and the precision of the created holes was the best among the tested punch profiles for all three groups of polymer composite belts. By combining the obtained results, in the form of shape factors $\beta$, with the perforation force approximation model, it is possible to calculate peak force value for the specified tool profile and belt type and use this data in the design process of the punching dies.
\end{abstract}

Keywords Spherical bowl piercing punch · Punching - Belt perforation · Vacuum conveyor belts · FEM analysis . Polymer composites

\section{Nomenclature}

$\beta \quad$ Shape factor

$\epsilon_{d m} \quad$ Strain at damage

$\epsilon_{p l}$

$v$

$\phi$

$\rho$

$\sigma_{\theta}$

$\sigma_{b}$

$\sigma_{c}$

$\sigma_{e q v}$

Dominik Wojtkowiak

dominik.wojtkowiak@put.poznan.pl

1 Faculty of Machines and Transport, Basics of Machine Design, Poznan University of Technology, ul. Piotrowo 3, 60-965 Poznań, Poland

2 Faculty of Mathematics, Physics, Technical Sciences, Kazimierz Wielki University in Bydgoszcz, 85-092 Bydgoszcz, Poland

-
-
-
-
$\mathrm{rad}$
$\mathrm{kg} / \mathrm{m}^{3}$
$\mathrm{MPa}$
$\mathrm{MPa}$
$\mathrm{MPa}$
$\mathrm{MPa}$

$\sigma_{r}$

Radial bending stress

$M P a$

$\tau_{s} \quad$ Shearing stress

$M P a$

$\xi \quad$ Compression area factor

$\xi \quad$ Critical compression area factor

$\xi_{\text {est }}$

A

Estimated compression area factor

Punch-belt contact area

$-$

$-$

$-$

$m m^{2}$

Compression distance of the scrap

Scrap compression area

$\mathrm{mm}$

$\mathrm{mm}^{2}$

$N \cdot s / m m$

$N \cdot \mathrm{mm}$

$D \quad$ Rigidity of the material

$-$

$M P a$

$N$

$N$

$N$

$F_{P D i} \quad$ Estimated peak perforation force $\quad N$

$F_{p l} \quad$ Perforation force at plastic deformation $N$

$F_{R \max }$ Rheological peak perforation force $\quad N$

$g \quad$ Thickness of the belt $\quad \mathrm{mm}$

$g_{P A} \quad$ Thickness of a polyamide core $\quad \mathrm{mm}$

$k \quad$ Elastic constant $\mathrm{N} / \mathrm{mm}$

$m_{\theta} \quad$ Circumferential bending torque $\quad N \cdot \mathrm{mm}$ 


$\begin{array}{lll}m_{r} & \text { Radial bending torque } & N \cdot \mathrm{mm} \\ \mu & \text { Friction coefficient } & - \\ p & \text { Pressure applied by moving punch } & \mathrm{MPa} \\ R & \text { Radius of the piercing punch } & \mathrm{mm} \\ r & \text { Radius of the lost contact area } & \mathrm{mm} \\ R_{e} & \text { Yield point } & \mathrm{MPa} \\ R_{m} & \text { Ultimate tensile strength } & \mathrm{MPa} \\ T & \text { Shearing force } & \mathrm{N} \\ v_{0} & \text { Velocity of the punch } & \mathrm{mm} / \mathrm{s} \\ w & \text { Deflection of the belt } & \mathrm{mm} \\ x & \text { Displacement of the piercing punch } & \mathrm{mm} \\ x_{d m} & \text { Displacement at damage } & \mathrm{mm} \\ x_{p l} & \text { Displacement at plastic deformation } & \mathrm{mm}\end{array}$

\section{Introduction}

Vacuum conveyor belts (Fig. 1) are commonly used to transport lightweight products, such as paper, foil, or cardboard as well as for transporting sheets [1]. Depending on the construction of the conveyor, either flat or toothed belts can fulfill the function of the conveyor belt. One of the most important stage of the manufacturing process for such belts is the perforation. Its goal is to make cylindrical holes, through which the air is sucked out to generate the vacuum between transported goods and the belt surface. Choosing a proper perforation method and its parameters is crucial for achieving the necessary properties of the product by ensuring good quality of the holes [2]. Perforation can be made by using either mechanical (punching and drilling) or non-mechanical methods including laser cutting and abrasive waterjet (AWJ). Although a non-mechanical method has an advantage that no contact forces between tool and material are present, which means no mechanical deformation of the belt and lack of friction wear of the tool, they are much more expensive than the mechanical ones. In addition, laser cutting is connected with hightemperatures, which may damage (melt) the structure and change its properties or cause thermal deformation, while AWJ is rather slow and the moist may cause delamination of the belt. Drilling also generates a lot of heat associated with friction and may cause delamination or pull the fibers out. Based on the theoretical analysis shown in [3], punching is the most suitable method for vacuum conveyor belts.

Due to the increasing requirements for the properties of the transmission and conveyor belts, composite structures were introduced into the belt structures and improved their strength and functional abilities. Basically we can distinguish three group of polymer composite belts [3]:

- elastic light belts with the core made of polyurethane, sometimes reinforced with polyester fabric, polyvinyl chloride (PVC), fabric, or rubber,

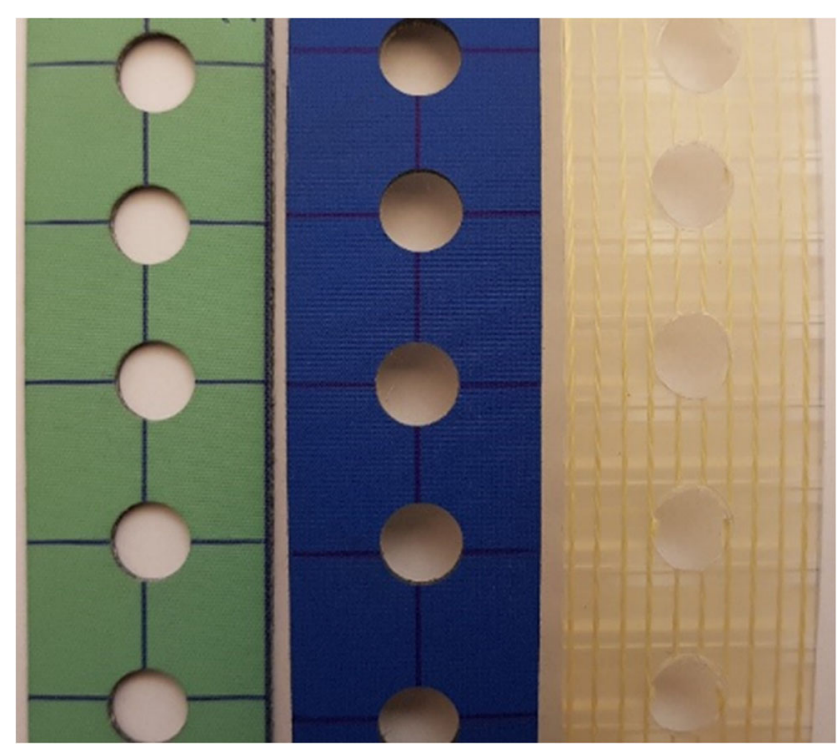

Fig. 1 Vacuum conveyor belts representing all three groups of polymer composite belts

- rigid belts with increased strength, the core of which is a layer of polyamide,

- durable, flexible polyurethane belts which are reinforced with aramid fiber (kevlar) cord.

Flat belts usually have the structure of a multilayer polymer composite (Fig. 2) and consist of core 1, protective gaskets 2, and two covers: load-carrying 3 and return 4. Otherwise, most common structures of toothed belts are fiber reinforced composites (Fig. 3), which consist of tension member 1 made of aramid, glass, carbon, or steel cord, which is placed between polyurethane or rubber teeth 2 and belt backing. In order to improve friction properties and reduce noise of operation, both sides of the timing belt can be coated with specially treated fabric. The application of composite structures in belt manufacturing greatly improved belt properties, which led to broadening the range of application for belt conveyors and transmissions. However, it also caused a lot of technical issues for manufacturers around the world by obstructing the machining process for this type of structures, among which the vacuum belt perforation occurs. That causes a lot of limitation in the production process like: perforating only the belts with a small profile and thin reinforced fibers, choosing the parts of the belt without the tension member present or limiting the hole diameter up to $6 \mathrm{~mm}$ [4]. It is hard to find one proper tool for all groups of polymer composite belts. In the case of elastic light belts, the main problem are uncut fibers, which indicates that sharpened cutting edges and lowest possible clearance value is recommended [2]. The same problem occurs when we perforate the belts reinforced with aramid cord. In that case using sharpened tools drastically lowers its durability, so 
Fig. 2 Multilayer composite flat belt construction based on Nitta PolyBelt TFL10S :

1 - polyamide (PA) core,

2 - polyamide fabric (PA fab)

gasket, 3-nitrile butadiene

rubber (NBR) load-carrying

cover, 4-nitrile butadiene

rubber (NBR) return cover

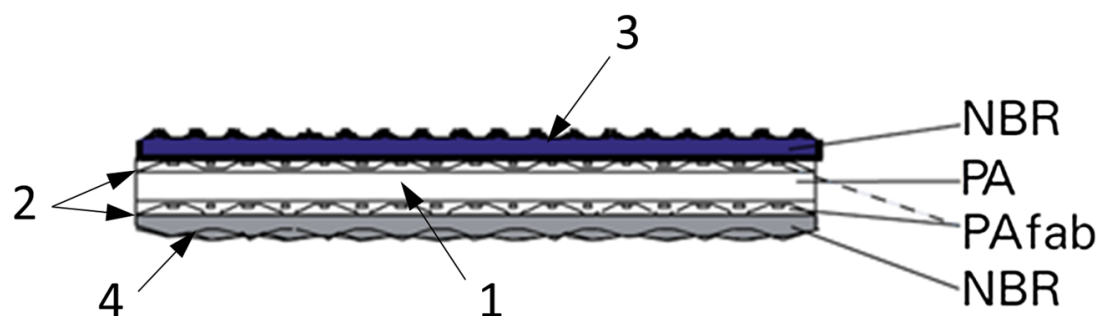

all tools must be made of hard and durable materials. The most problems are noticeable for rigid belts with increased strength, which causes a necessity of using very high force. Besides, multiple defects can be observed in the products like ovality and conicity of the holes, uneven side surfaces and deformed contours of the holes [2]. For that reason the authors focus on that group of belts in their research.

Based on that the authors decided to improve the belt punching method by developing a series of research including analytical and numerical modelling of the perforation process as well as empirical tests made on the designed piercing die. The obtained results will be used in the design process of the automatic machine for precise mechanical belt perforation.

In this paper, the authors focused on modelling the punching process with regards to the influence of the punch profile on the force needed to perform belt perforation. In Section 2, the authors discussed the basics of the belt punching process and analyzed known punch shapes. In Section 3, complex analysis of punching mechanics was made and analytical stress model for belt perforation was introduced. Section 4 presents the methodology and the

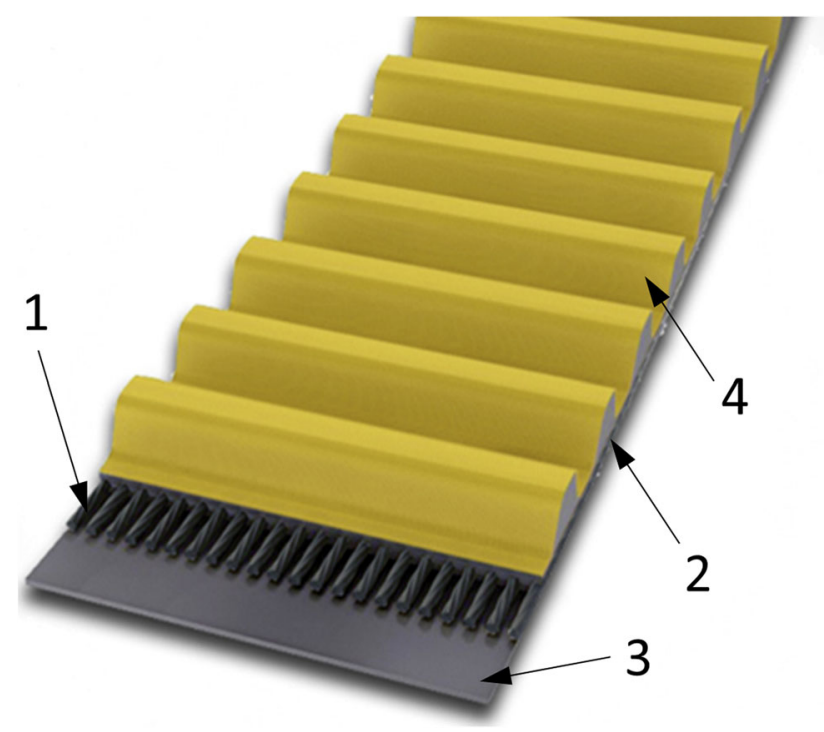

Fig. 3 Fiber reinforced composite timing belt construction based on CONTI SYNCHROCHAIN: 1-tension member made of aramid, 2-polyurethane (PU) teeth, 3-polyurethane belt backing, 4-fabric coating punching die construction used in empirical tests. Based on the proposed model, the analysis of estimate peak value of perforation force in the belt punching for the flat piercing punch was made and shown in Section 5. Section 6 contains the validation of the model using FEM tests. In Section 7 the authors presented results of belt perforation with the designed punching die and selected punch profiles, which were used to calculate shape factors. Described methodology of estimating the perforation force taking into consideration the shape of the piercing punch, which consists of analytical, empirical, and numerical analyses, was later validated using types of belts different than the ones used for modelling. Following results were presented in Section 8. The last section contains a brief summary, conclusions, and future research plans.

\section{Perforation of vacuum conveyor belts with punching}

In punching, holes are made by mechanical cutting, which is a result of high stress on the shear surfaces necessary to overcome the cohesion of the material. The cutting work is performed by a rigid tool which, by moving, generates the pressure on the shaped material. The punching process can be carried out with either one or two cutting edges, constituting a closed contour. In the first case, the cutting tool is a sharpened hollow punch, which cooperates with the reducer plate. More often punching is made with two cutting edges, where a cylindrical punch cooperates with the punching die $[3,5,6]$. The basic types of tools used for mechanical belt punching are shown in Fig. 4. The mechanics of punching with two cutting edges enables a lot of possibilities to impact on the force characteristic by modifying the punch or die geometry. This is the main reason why the authors concentrated on this method of punching in the following research.

Having analyzed the available literature, it is clearly visible that metal sheet punching has been widely researched [7-18] and there is a lot of information about the influence of the geometrical features of the piercing punch and die [7, $12,18]$ as well as process parameters $[15,16]$ on perforation force and quality of the holes. However, it is very hard to find research papers about punching the polymer composite 
Fig. 4 Basic types of piercing punches. a, b Hollow piercing punches which cooperate with the reducer plate with the or inside. $\mathbf{c}$ Flat piercing punch with the piercing die cutting edge towards outside (a) a

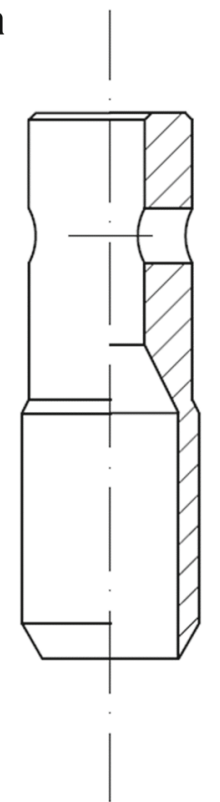

b

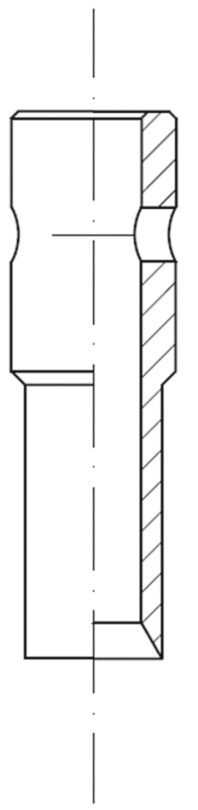

C

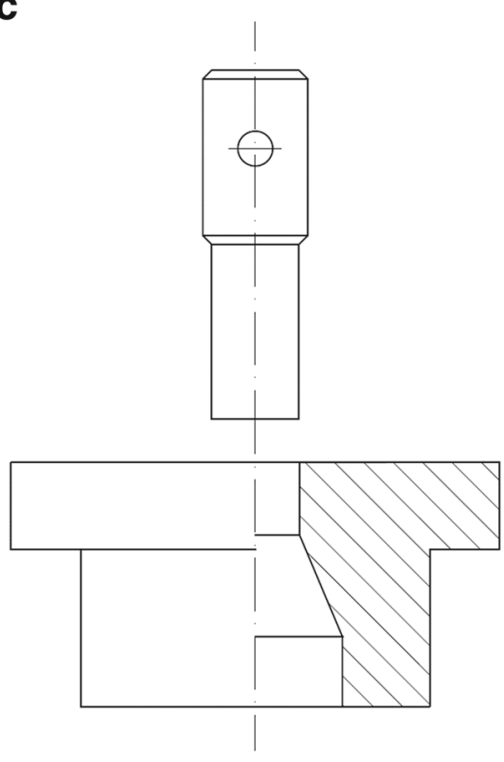

structures. Zain et al. [19] tested the effect of the puncher profile on the precision of punched holes. Chan et al. [20] tested the influence of die clearance on the perforation load and hole quality. Lambiase and Durante [21] characterized the mechanical behavior of the punching holes in laminates and made a comparative research between drilling and punching. Pramono et al. [22] performed punch shear tests on the bamboo fibers reinforced polymer composites. All of the previously mentioned papers were concentrated strictly on the rigid composite panels and none of the above analyzed the perforation of the elastic products such as conveyor and timing belts. Even in the literature connected with machining of polymer composites the main focus is on the laser cutting, AWJ, and drilling. For that reason modelling vacuum belts perforation process can be very useful in improving the design process of the dedicated machines.

Despite the lack of information for punching the composite belts, some data acquired from researching metal punching can be adjusted and applied to describe the belt perforation process. It is proved by many different test results presented in research papers that the clearance between the piercing punch and die has a crucial influence on perforation force and quality of the punched holes [7, 12, 18, 20]. This phenomenon can be observed in belt perforation as well, however the obtained characteristics may slightly differ. A lot of research shows that the a

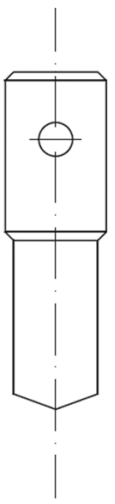

b

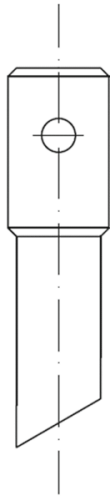

C

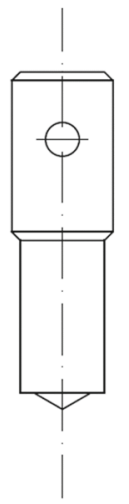

d

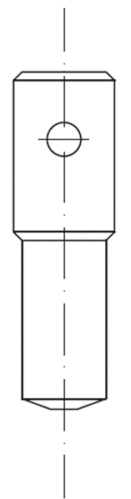

Fig. 5 Modified types of piercing punches [8-10, 13, 16, 19, 22, 2429]. a, b, c Convex punch profiles: V-shaped chamfered punch (a), single sheared punch (b), and punch with a conical pilot (c). d, e Convex punch profiles: chamfered flat punch $(\mathbf{d})$, dual stage punch. f, $\mathbf{g}$, e

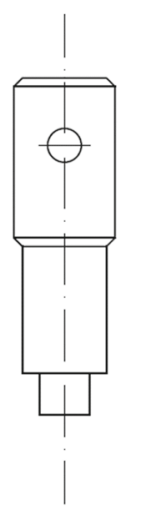

$\mathbf{f}$

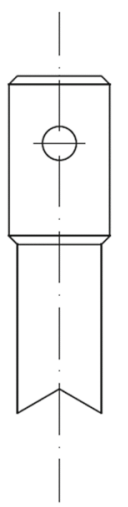

g

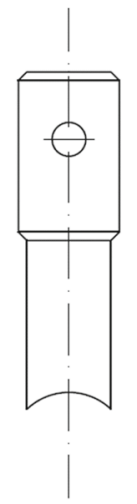

h

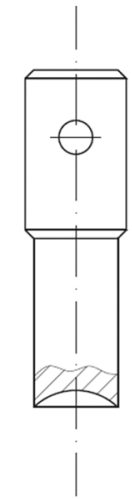

h Concave punch profiles: double sheared (inverted chamfered) punch (f), punch with cylindrical bowl (g), punch with spherical bowl (h) 
geometrical features of the piercing punch may also have an important effect on the change of analyzed parameters. A flat-end tool is the basic type of the piercing punch because of its simple geometry and ease of sharping, which has a positive effect on manufacturing and maintenance. On the other hand, their cutting force is relatively high and a sudden force drop generates a lot of noise [23]. It may also lower the precision of the punched holes. In order to reduce the force, geometrical features of the piercing punch face may be modified [24]. Over the years of research multiple different shape modifications of the piercing punch were proposed. Based on the literature analysis 8 shapes that have the most potential in being an effective geometry for multilayer polymer composite belts have been chosen and presented in Fig. 5.

Singh et al. [24] proposed in their work various punch shapes and analyzed their stiffness by using FEM methods, which is a very important factor in the punchdie cooperation. Basically, we can distinguish three types of modified tools: concave, convex, and flat. In convex tools face surfaces are tilted at a desired angle to its axis. There are three main convex punch profiles: $\mathrm{V}$-shaped chamfered punch [8, 13, 24], single sheared punch [19, 22, 24, 25], and punch with a conical pilot [19]. The main principle of operation for convex tools is to fracture the structure of the material in order to soften it before the closed contour cutting appears or even divide the cutting on the circumference of the hole in order to minimize the length of the cutting edge, which does the cutting work at one time. Flat modified tools are characterized by leaving the face surface and changing the shape of the cutting edge. It can be obtained by chamfering or rounding the cutting edge $[10,19,26]$ and grading the diameter along the punch axis - tapered punch $[9,27]$ or multistage punch $[16,28]$. A separate group of flat modified tools are the punches which have a coating on their work surface. There is also a hybrid type of modified punches proposed by Uddeholm company, which is a V-shape section [13]. The last group of modified piercing tools are concave tools, which are made by removing the material from the inside of the punch in order to create sharp cutting edges. It has a positive effect on changing the compression-shearing ratio in the perforation process, but due to the complex geometry they are harder to manufacture and sharpen. This group of tools will also have the lowest durability among all the punches, which is why it is necessary to use materials with high strength and increase the hardness by heat treatment. We can distinguish a double sheared (inverted chamfered) punch [13, 24], inverted cup punch [19, 24], wave curved cutting edge punch [23], punch with cylindrical bowl [24] and the punch with spherical bowl [29]. Although the punch with a spherical bowl was introduced in the patent [29], no traces of analysis of this type of tool have been found. The goal of this research is to make a comparative analysis of the effect of the piercing punch shape on perforation force and to choose the most adequate type of tool modification for the composite belt perforation.

\section{Modelling the punching process using a piercing punch and a die}

The perforation process of punching with two cutting edges (a piercing punch and a die) can be divided into the following stages [10-12, 18, 21, 24, 30]:

I. elastic material deformation,

II. elastic-plastic material deformation,

III. plastic flow,

IV. cracking,

V. failure,

VI. separation of the scrap from the material and pushing it through the die.

A theoretical characteristic of the force during the belt perforation process divided for all the above mentioned stages was shown in Fig. 6 and the schematic visualization was presented in Fig. 7.

The first stage of the perforation process occurs when the contact between the piercing punch and the belt is detectable. Pressure generated by the punch, which moves along the vertical axis, causes elastic bending of the material. The deflection curve depends on the rigidity of the material and its fixing. Because of the closed contour of the cutting edge, part of the material, which is spent to the scrap, works as a circular plate loaded with pressure. Regardless on the fixing type (with or without the blank holder, which block the rising of the material), compression of the belt occurs in the areas closest to the cutting edges of punch and die. Sizes of these areas depend strictly on the thickness of

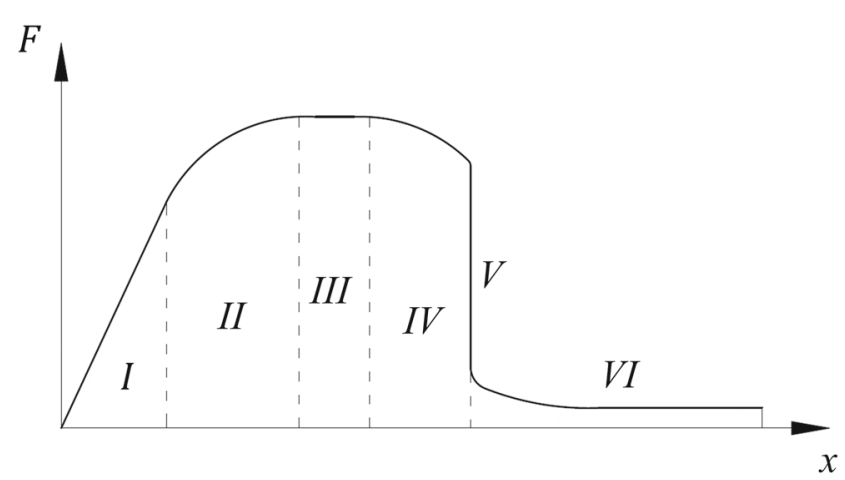

Fig. 6 Theoretical force characteristic in function of the punch displacement in the belt perforation process 

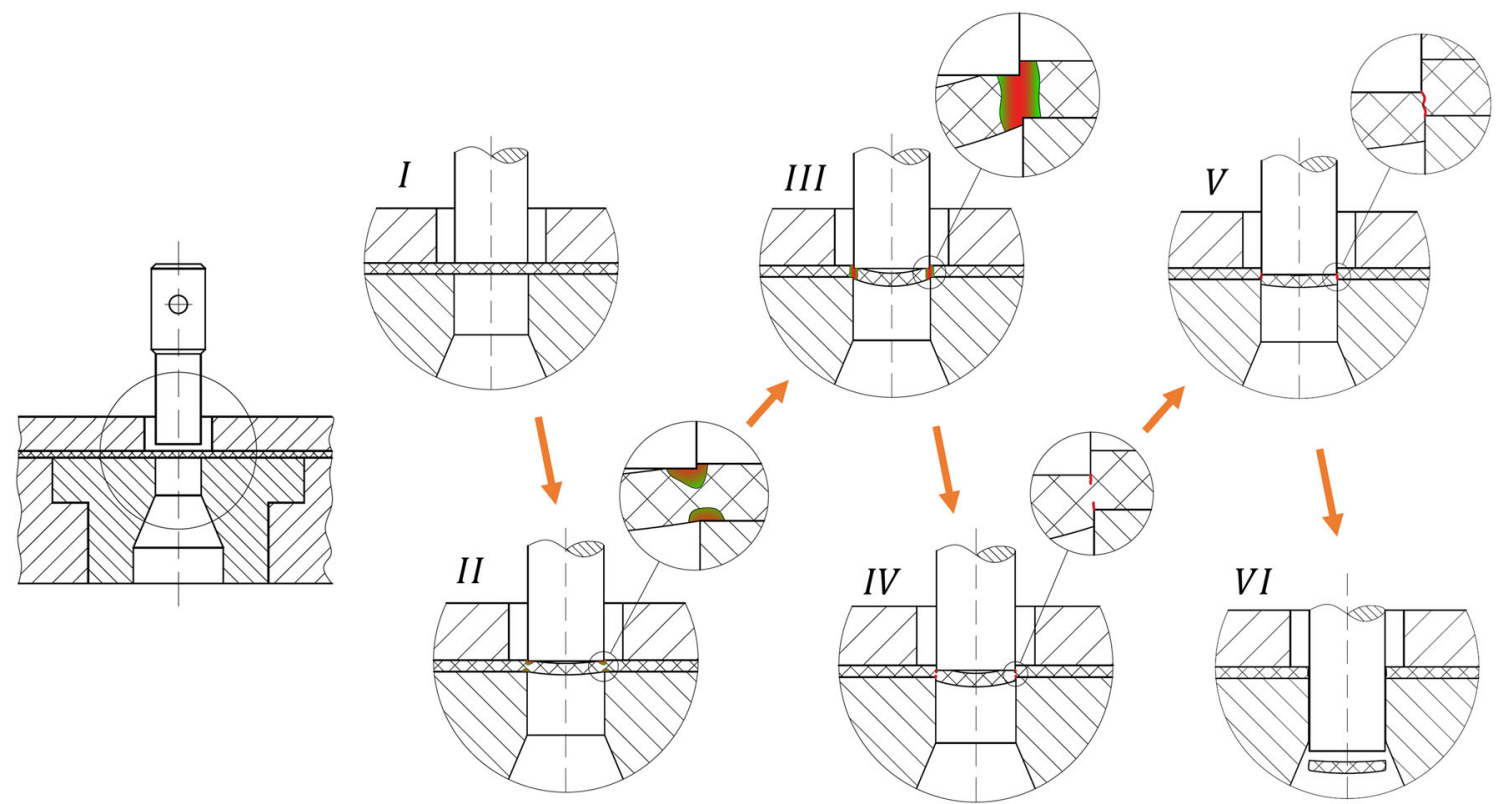

Fig. 7 Schematic of the stages of belt perforation process

the belt and geometrical features of the punching tools - the diameter of the punch and the clearance between the cutting edges. Further displacement of the punch causes the growth of the belt deformation, which has a linear influence on the perforation force increase - elastic range of the process (I). As a consequence of higher force, the deflection increases and its curve changes. This leads to a decrease in the contact

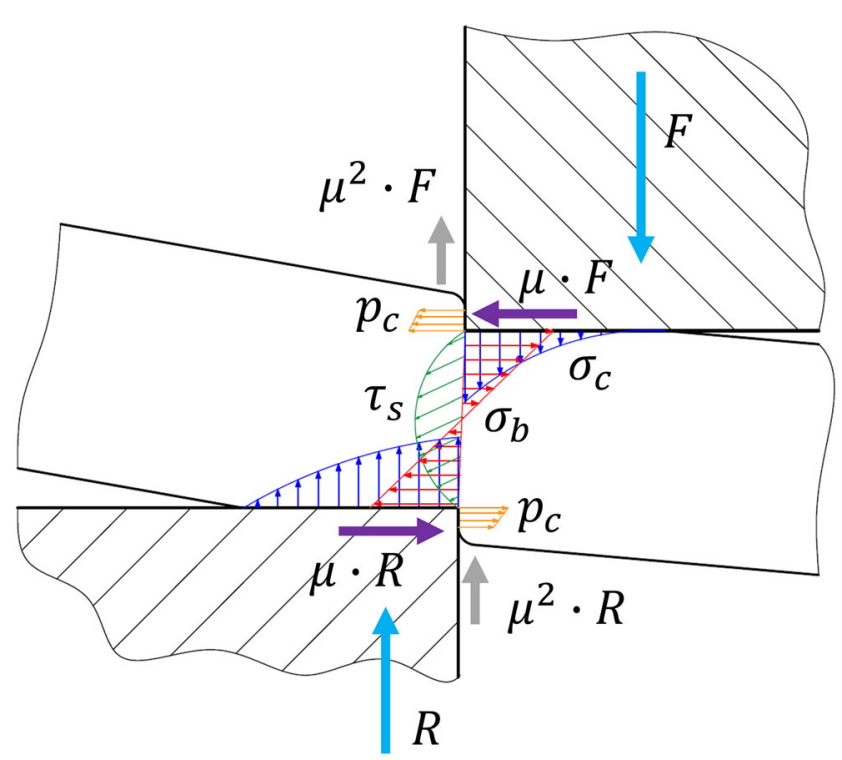

Fig. 8 Load and stress distribution in the sheared cross section of a punched material: $F$-perforation force, $R$-reaction force, $\mu-$ coefficient of friction, $\sigma_{b}$-bending stress (red), $\sigma_{c}$-compression stress (blue), $\tau_{s}$-shearing stress (green), $p_{c}$-contact pressure (orange) area between the punch and belt and the contact stress rises sharply. It shows that the state of stress in the punching process is complex and along the cutting edge it consists of normal stress (bending and compression), tangential stress (shearing), and contact stress (Fig. 8). It indicates that a strength hypothesis is necessary to properly calculate stress in the sheared cross section.

Because multilayer polymer composite belts have orthotropic mechanical properties, they are much more rigid in the transverse direction than in the longitudinal direction. That is why the surface which loses the contact with the punch due to the deflection is elliptical instead of circular (Fig. 9). It is obvious that arrangement and thickness of all the layers will affect the characteristic of the perforation process. However, for comparative analysis, it is possible to simplify the proposed model to the isotropic one by using averaging mechanical properties of the belt [31-34].

When the stress level reaches the yield point, the material starts to deform plastically. Stress distribution in the sheared cross section is non-uniform and its critical value occurs the fastest in the contact area between the cutting edge (especially of the punch) and the belt. After plastic deformation of the material occurs, the work hardening is still present, but its rate decreases with the further displacement of the punch - nonlinear range of perforation force characteristic (II). After the stress level in the whole cross section overcomes the yield point, two previously separated plastic areas connect into one and allow for the plastic flow (III). During this stage, force does not change its value with the increase of the plastic strain. If the plastic strain reaches the limit value, the cracking near the place 
Fig. 9 Schematic of the difference between isotropic and orthotropic materials behavior during punching
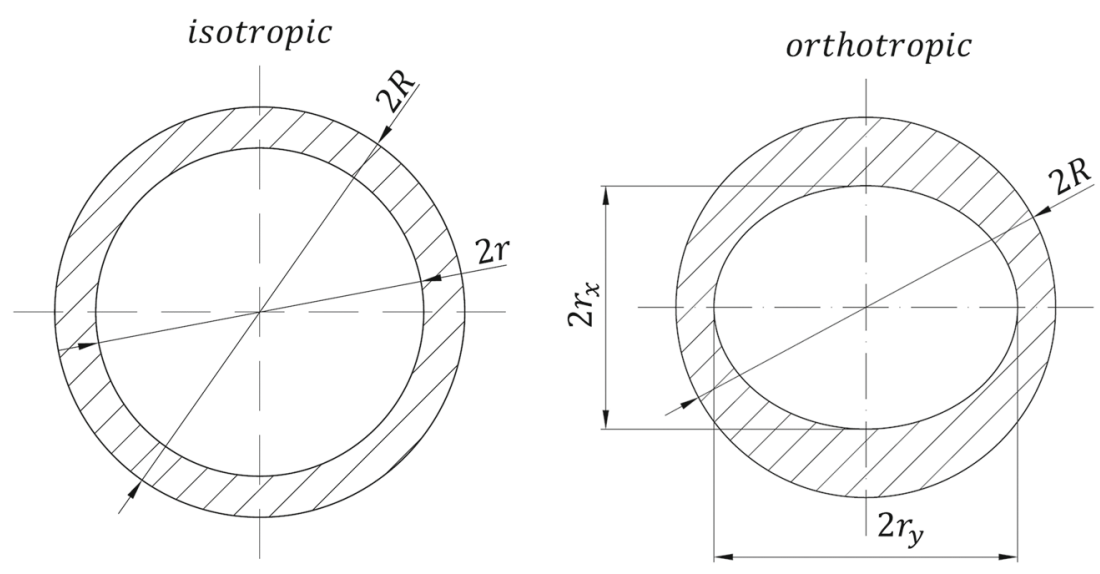

where the cutting edge cooperates with the material occurs (IV). This phenomenon is mostly observed in the core of the belt, which is the most rigid part of the composite and has a tendency to brittle fracture. Continuous movement of the punch leads to crack propagation, which causes failure of the material when two fracture lines meet. Before it happens, we can observe a fall of the perforation force due to the lowering of belt rigidity caused by decreasing thickness of the undisturbed structure of the material. When the failure occurs, there is a sudden drop of perforation force value $(\mathrm{V})$, which is an effect of releasing accumulated energy in the compressed material and tensed construction elements of the punching die. After that, force still has some non-zero value, which is the result of the resistance connected with separating the scrap from the base material and friction between the scrap or the material and the side surface of the punch or the inner surface of the die hole (VI).

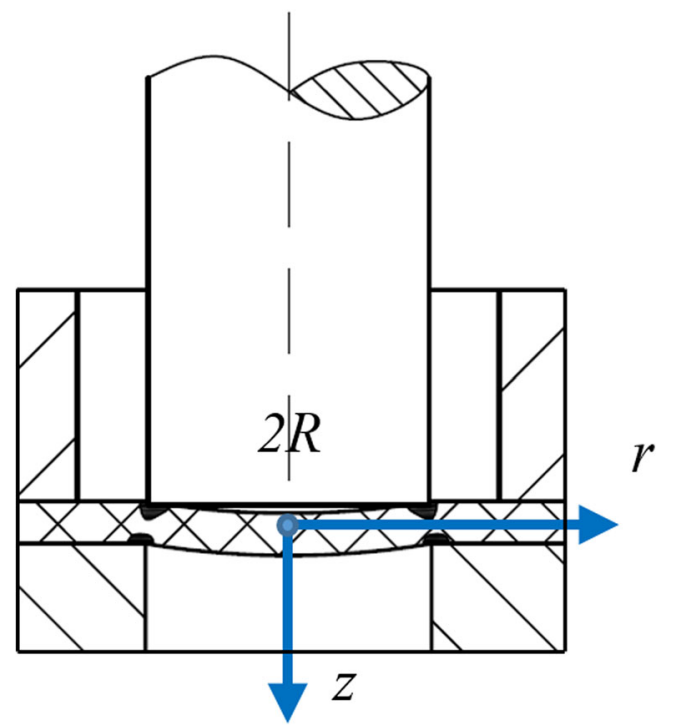

Fig. 10 Polar coordinate system used in proposed model of belt perforation
Based on the presented analysis, it is clearly visible that the clearance between the piercing punch and the die has a crucial influence on the characteristic of the perforation process. By changing its value, we change the deflection curve, size of the plastic areas, and cracking propagation direction, which has an effect on the quality of the side surface of the hole. However, when we discuss polymer composite materials which have rather small rigidity, it is possible to assume using the smallest value of the clearance - close to 0 , which makes it possible to perform the perforation. Thanks to that it is possible to focus strictly on the stress level in the sheared cross section of the belt.

Based on the abovementioned analysis of the punching process, the following model was derived. Two cases were analyzed: with and without the pressure plate. During the model development both isotropic and orthotropic mechanical properties were taken into consideration.

Basic differential equation for bending the circular plate in the polar coordinate system $(r, \theta, z)$-Fig. 10-which was the base for the model derivation was shown in Eq. 1 [35, 36]:

$\frac{d}{d r}\left[\frac{1}{r} \frac{d}{d r}\left(r \frac{d w}{d t}\right)\right]=\frac{T}{D}$

where: $w(r)$-deflection of the material [mm], $T$-shearing force [N], $D$-rigidity of the material [Nmm].

Equations used to calculate shearing force and rigidity of the material was presented in Eqs. 2 and 3 [35]:

$T=\frac{p r}{2}$

$D=\frac{E g^{3}}{12\left(1-v^{2}\right)}$

where: $p$-pressure applied by moving punch $[\mathrm{MPa}], E-$ Young's modulus [MPa], $g$-thickness of the belt $[\mathrm{mm}]$, $v$-Poisson's ratio [-].

General solution for the Eq. 1, which contains equations for deflection angle $\phi$, deflection $w$ and both bending 
torques (radial $m_{r}$ and circumferential $m_{\theta}$ ) was presented consecutively in Eqs. 4-7 [35]:

$\phi=\frac{d w}{d t}=\frac{C_{2}}{r}+C_{1} \frac{r}{2}+\frac{p r^{3}}{16 D}$

$w(r)=C_{3}+C_{2} \ln r+C_{1} \frac{r^{2}}{4}+\frac{p r^{4}}{64 D}$

$m_{r}=-D\left[(1+v) \frac{C_{1}}{2}+(1-v) \frac{C_{2}}{r^{2}}\right]-\frac{3+v}{16} p r^{2}$

$m_{\theta}=-D\left[(1+v) \frac{C_{1}}{2}+(1-v) \frac{C_{2}}{r^{2}}\right]-\frac{1+3 v}{16} p r^{2}$

where $C_{1}, C_{2}$, and $C_{3}$ are the integration constants.

In order to find a particular solution of the differential equation, it is necessary to know the boundary conditions. The method used to model holding the belt with a blank holder or leaving the belt unfixed along with proper boundary conditions for both cases was shown in Fig. 11.

If we take into account boundary conditions for belt perforation with a blank holder, we obtain the following integration constant:

$C_{1}=-\frac{p R^{2}}{8 D}, C_{2}=0, C_{3}=\frac{p R^{4}}{64 D}$

Based on that we receive particular solutions for this case shown in Eqs. 9-12:

$\phi=\frac{d w}{d t}=-\frac{p}{16 D}\left(R^{2} r+r^{3}\right)$

$w(r)=\frac{p}{64 D}\left(R^{2}-r^{2}\right)^{2}$

$m_{r}=-\frac{p}{16}\left(R^{2} v-r^{2} v+R^{2}-3 r^{2}\right)$

$m_{\theta}=-\frac{p}{16}\left(R^{2} v-3 r^{2} v+R^{2}-r^{2}\right)$
Bending torques on the contour of the punched hole $(r=R)$ equal:

$m_{r}=\frac{p R^{2}}{8}, m_{\theta}=\frac{p R^{2} v}{8}$

This implicates that bending stress can be calculated from the Eqs. 14-16:

$\sigma_{r}=\frac{12}{g^{3}} m_{r} z=\frac{3 p R^{2}}{2 g^{3}} z$

$\sigma_{\theta}=\frac{12}{g^{3}} m_{\theta} z=\frac{3 v p R^{2}}{2 g^{3}} z$

$\sigma_{b}=\sqrt{\sigma_{r}^{2}+\sigma_{\theta}^{2}-\sigma_{r} \sigma_{\theta}}=\frac{3 p R^{2}}{2 g^{3}} z \sqrt{v^{2}-v+1}$

By analyzing the final equation for bending stress, we can observe that its highest value occurs on the surface of the belt, where the contact between the punch and the material is present. However, the maximal distance from the neutral axis changes during the perforation due to the penetration of the material by the piercing punch and can be described with the following equation:

$z=\frac{g-x}{2}$

where $x$ is a displacement of the piercing punch [mm].

If we consider the perforation without fixing the belt with a blank holder, the bending stress equation will be looking as follows:

$\sigma_{b}=\sqrt{\sigma_{r}^{2}+\sigma_{\theta}^{2}-\sigma_{r} \sigma_{\theta}}=\sigma_{b}=\frac{3(1-v) p R^{2}}{2 g^{3}} z$

In order to determine the contact pressure between the punch and the belt we can use Eq. 19:

$p=\frac{F(x)\left(1-\mu^{2}\right)}{A(x)}$

Fig. 11 Methodology of determining the boundary conditions for belt punching

$$
\varphi(0)=0, w(R)=0, \varphi(R)=0
$$
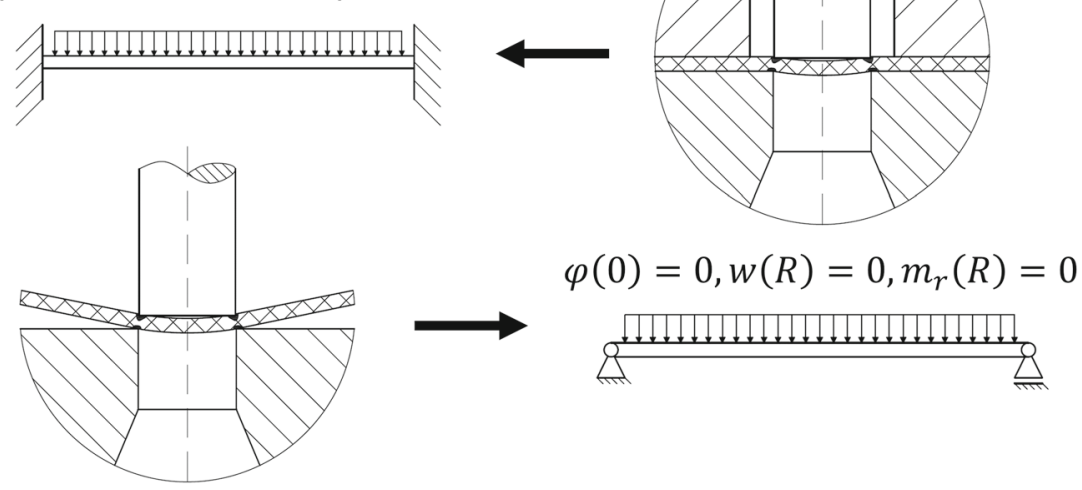
where $F(x)$-force applied by moving punch $[\mathrm{N}], \mu-$ friction coefficient [-], $A(x)$-contact area between the punch and the belt $[\mathrm{mm}]$.

Lowering the force taken into calculation of the pressure is caused by the frictional resistance between the belt and both cutting tools. Contact area is the function of a displacement of the piercing punch, however, if total displacement is higher than deflection of the material, the whole face of the punch presses the belt. If not, this value can be calculated by using two different approaches connected with isotropy or orthotropy of belt mechanical properties (Fig. 9). In both cases, the radius of the disengaged area is calculated by comparing the displacement $x$ and the radius $r$. The difference in the case of materials with orthotropic mechanical properties is that it is necessary to analyze the deflection curve in both longitudinal and transverse direction, which indicates the elliptical shape of the face surface that loses contact with the belt during perforation. Based on that, the calculations for isotropic materials should be made according to Eqs. 2022 , and for orthotropic materials we should use formulas (23)-(25):

$A(x)=\pi R^{2}-\pi r^{2}(x)$

$x=w(r)=\frac{p}{64 D}\left(R^{2}-r^{2}\right)^{2}$

$r(x)=\sqrt{R^{2}-8 \sqrt{\frac{D x}{p}}}$

$A(x)=\pi R^{2}-\pi r_{x}(x) r_{y}(x)$

$r_{i}(x)=\sqrt{R^{2}-8 \sqrt{\frac{D_{i} x}{p}}}$

$D_{i}=\frac{E_{i} g^{3}}{12\left(1-v^{2}\right)}$

In order to calculate the compression stress, it is necessary to determine the area of compression. The percentage value of the scrap area, which will be compressed in the punching process, differs and the Young modulus to thickness ratio has a strong dependence on its value. In the proposed model, this value was determined with $\xi$ factor and its characteristic is derived in Section 5. If the area of compression is bigger than the contact area, we should use the smaller value instead.

$$
\begin{aligned}
& \sigma_{c}=\frac{F(x)\left(1-\mu^{2}\right)}{A^{\prime}(x)} \\
& A^{\prime}(x)=\pi R^{2}\left(1-\xi^{2}\right)
\end{aligned}
$$

Shearing stresses can be calculated using the following equation:

$\tau_{s}=\frac{F(x)\left(1-\mu^{2}\right)}{g l_{c}}=\frac{F(x)\left(1-\mu^{2}\right)}{2 \pi R g}$

where $l_{c}$ is the length of the cutting edge [mm].

If all the stresses are calculated, the equivalent stress in the sheared cross section for a fixing wih a blank holder can be calculated based on the Huber-Mises-Hencky yield criterion [37] (Eqs. 29-32):

$\sigma_{e q v}=\sqrt{\sigma_{b}^{2}+\sigma_{c}^{2}-\sigma_{b} \sigma_{c}+3 \tau_{s}^{2}}$

$\sigma_{e q v}=F(x)\left(1-\mu^{2}\right) \sqrt{\lambda_{b}+\frac{1}{A^{\prime}(x)^{2}}-\lambda_{b c}+\frac{3}{4 \pi^{2} R^{2} g^{2}}}$

$\lambda_{b}=\frac{9 R^{2}(g-x)^{2}\left(v^{2}-v+1\right)}{16 A(x)^{2} g^{6}}$

$\lambda_{b c}=\frac{3 R^{2}(g-x) \sqrt{v^{2}-v+1}}{4 A(x) A^{\prime}(x) g^{3}}$

Thanks to the proposed model, we are able to determine the stress level in the sheared cross section of the perforated belts based on the force characteristic in function of displacement and material data obtained from basic strength tests (tensile, compression and shearing). However, the model can be inverted and used to determine the peak force value, based on the Eq. 33, which is necessary in the design process for punching dies.

$$
F\left(\sigma_{e q v}, x\right)=\frac{\sigma_{r e d}}{\left(1-\mu^{2}\right) \sqrt{\lambda_{b}+\frac{1}{A^{\prime}(x)^{2}}-\lambda_{b c}+\frac{3}{4 \pi^{2} R^{2} g^{2}}}}
$$

Based on the theoretical analysis of the process, the maximum value of the force is when the plastic flow occurs and the cracking is not present yet. This means that to determine peak value we need only the force characteristic model in the elastic-plastic range. For that cause, we can use the rheological model (Bingham model) [38] shown in Fig. 12.

In this model, if the force is lower than $F_{p l}$ value, it will work as an elastic body with linear constant $k$. However, when the limit force is exceeded, the behavior of the material can be described with the following equation (Maxwell model) [39]:

$k \cdot b \cdot \frac{d x(t)}{d t}=b \cdot \frac{d F(t)}{d t}+k \cdot F(t)$ 
Fig. 12 Rheological model of perforation force in elastic-plastic range

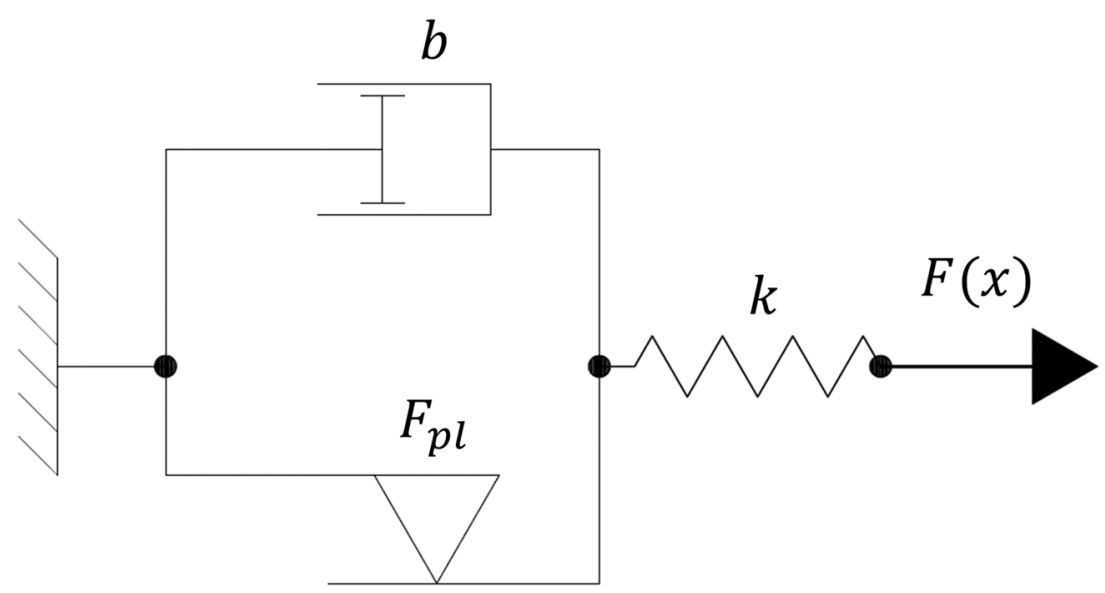

If the kinematic extortion will be a linear function (35), the result force can be determined with Eq. 36.

$x(t)=v_{0} t, \frac{d x(t)}{d t}=v_{0}$

$F(t)=-b \cdot v_{0} e^{\frac{b t}{k}}+b v_{0}$

In conclusion, the model for estimation of the force characteristic in the elastic-plastic range of the punching process can be described as follows:

$F(x)= \begin{cases}k x & \text { if } F(x)<F_{p l} \\ b \cdot v_{0}\left(1-e^{\frac{b\left(x-x_{p l}\right)}{k \cdot v_{0}}}\right) & \text { if } F(x) \geq F_{p l}\end{cases}$

\section{Methodology of research}

In order to validate the proposed model, it is necessary to perform a series of punch shear tests for different types of belts and selected piercing punches with various punch profiles. For that application, a proper test stand was designed and built (Fig. 13). The punching die consists of two thick and rigid rectangular parts: $40-\mathrm{mm}$ thick base 1 and 30-mm thick head block 2, which can move along the vertical axis. In order to maintain the fit between the piercing punch 8 and the die 9 , the head block is guided by a set of four zero backlash linear guides. Each guide consists of the guiding column 3 , the sleeve 4 and the ball bushing 5 . Thanks to that, even for very small values of clearance $(0.05 \mathrm{~mm})$, the solution can be ensured to be stable during a series of tests. The mounting of the piercing punch is made using a special chuck 7 with a cylindrical hole in its face with a precise fitting with a grip segment of the piercing punch. Force is transferred by a contact between the flat bottom surface of the hole and the top flat surface of the grip segment and the axial displacement is disabled using a pin. The chunk in mounted in a precise socket in the punch plate 6 , which is connected with the head block by screws. The die is embedded in the base by fitting it with a precise socket. All the sockets were made in one gripping in order to
Fig. 13 Punching die and all the tools used in presented tests: 1-base, 2-head block, 3-guiding column, 4-sleeve, 5-ball bushing, 6-punch plate, 7-punch chuck, 8piercing punch, 9-die, 10-belt specimen, 11-pressure plate

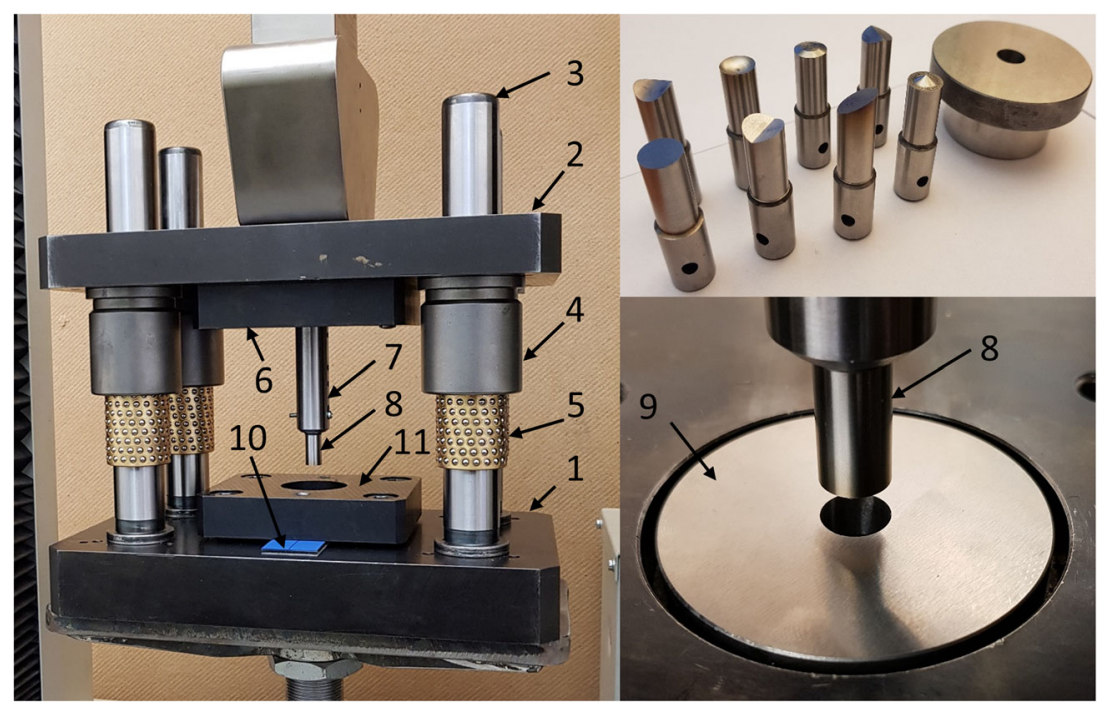


Fig. 14 Specimen of TFL10S belt used in a belt perforation research

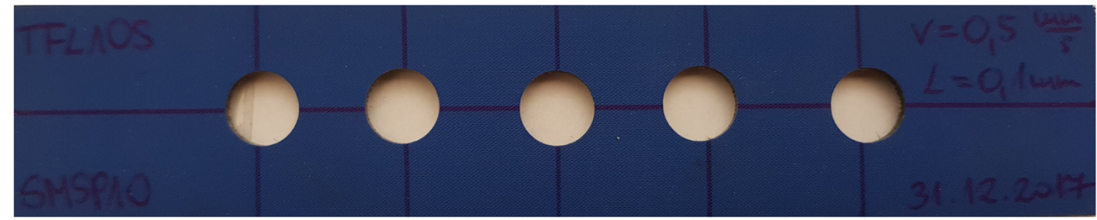

ensure the concentricity. Rectangular specimen 10 is placed on the top surface of the base and fixed with the pressure plate 11 , which is bolted to the base. Due to the usage of the screw connection we are able to regulate the pressure applied to the belt specimen.

For the empirical testing, MTS insight testing system with load capacity $50 \mathrm{kN}$ was used. All the tests were performed with the speed of traverse $0.5 \mathrm{~mm} / \mathrm{s}$, in order to maintain quasi-static nature of the research. For the tests, eight different geometries of the piercing punch with diameter $10 \mathrm{~mm}$ were used. All shapes were chosen by the literature analyses presented in Section 2 as presented in Fig. 5. During preliminary research, the dual stage piercing punch was eliminated as it was not fulfilling the hole precision criteria. According to the previous analysis of the belt perforation process, the value of the clearance was established at $0.1 \mathrm{~mm}$, which is $1 \%$ of the punch diameter. In order to have a wide spectrum of data, tests were performed for 10 different types of belt produced by Nitta. Eight of them represent the group of belts with polyamide core (SG500, TTA500N, TTA1000N, M500, TFL7S, TFL10S, TFL15S, XH500-6). Other two represent the remaining groups (flat belt with polyurethane reinforced with polyester fabric core LAB12E and toothed belt with aramid fibers $\mathrm{T} 10 \mathrm{~K})$. For each belt, the rectangular specimen $30 \times 150$ $\mathrm{mm}$ was cut and five holes spaced $20 \mathrm{~mm}$ were made (Fig. 14). During the tests, force and displacement of the punch were recorded as $F(x)$ characteristics.

\section{Estimation of the peak value of the perforating force for belt punching with a flat piercing punch}

The main application for the proposed model is to estimate the peak value of perforating force based on

Table 1 Mechanical properties of the selected types of belts

\begin{tabular}{llllllll}
\hline $\begin{array}{l}\text { Type } \\
\text { of belt }\end{array}$ & $\begin{array}{l}g \\
{[\mathrm{~mm}]}\end{array}$ & $\begin{array}{l}g_{P A} \\
{[\mathrm{~mm}]}\end{array}$ & $\begin{array}{l}E \\
{[\mathrm{MPa}]}\end{array}$ & $\begin{array}{l}v \\
{[-]}\end{array}$ & $\begin{array}{l}\mu \\
{[-]}\end{array}$ & $\begin{array}{l}R_{e} \\
{[\mathrm{MPa}]}\end{array}$ & $\begin{array}{l}R_{m} \\
{[\mathrm{MPa}]}\end{array}$ \\
\hline M500 & 2.5 & 0.5 & 201 & 0.3 & $0.5-0.6$ & 57 & 88 \\
TFL7S & 2.4 & 0.7 & 220 & 0.23 & $0.5-0.6$ & 98 & 150 \\
TFL10S & 2.6 & 1 & 235 & 0.2 & $0.5-0.6$ & 110 & 173 \\
TFL15S & 3.1 & 1.5 & 289 & 0.31 & $0.5-0.6$ & 108 & 232 \\
\hline
\end{tabular}

the selected mechanical properties of polymer composite belts. Necessary values which will be needed for the calculations are presented in Table 1. In order to acquire all the values, the proper strength test must be performedthe uniaxial tensile, compression test, and the shear test. The methodology of performing and analyzing the results of such tests for polymer composite belts along with the description of necessary equipment is presented in [31]. The first two parameters from the table (thickness $g$ and core thickness $g_{P A}$ ) are the simple geometrical features and can be easily measured with contact or non-contact methods. Young's modulus $E$ can be obtained from the compression test. In the case of multilayer composite belts, we can distinguish two different Young's modulus. The first one is connected with the hyper elastic rubber cover and the second one (after hardening occurs) strictly depends on the core parameters. If we consider homogenization of the composite mechanical properties for the cutting analysis, we should take into account the more dominant value, which defines the cutting resistance of a material. In the case of the belt it will always be the core or a tension member $[31,32]$. This approach can be explained by analyzing the structure of the multilayer composite as springs connected in a series to each other. In that case, during compression, the stress level in all layers is the same, but because the stiffness of the core is much greater than other layers, its strain will be the lowest. This is why in the first stage basically only the rubber covers of the belts deform, and the core is engaged in the material strength in the second stage of compression. This is the simplest model for composite mechanical properties homogenization [31, 32].

The explanation presented above is also applicable for Poisson ratio $v$ and it can be calculated from mixing Young's and Kirchoff's moduli $G$, which can be gained by performing both compression and shear tests. These values can be also estimated by using the model proposed by authors in [31]. In order to determine yield point $R_{e}$ and tensile strength $R_{m}$, it is necessary to do a uniaxial tensile test. Because the visible yield point is not present in the belt tensing characteristic, the value can be obtained by finding the point where the theoretical linear function starts to differ from the empirical characteristic by more than 1 $\mathrm{MPa}$. Tensile strength can be defined as the value of stress for which the belt brakes.

The last needed parameter, which is a friction coefficient $\mu$ can be taken from the datasheet of the belt. However, it 

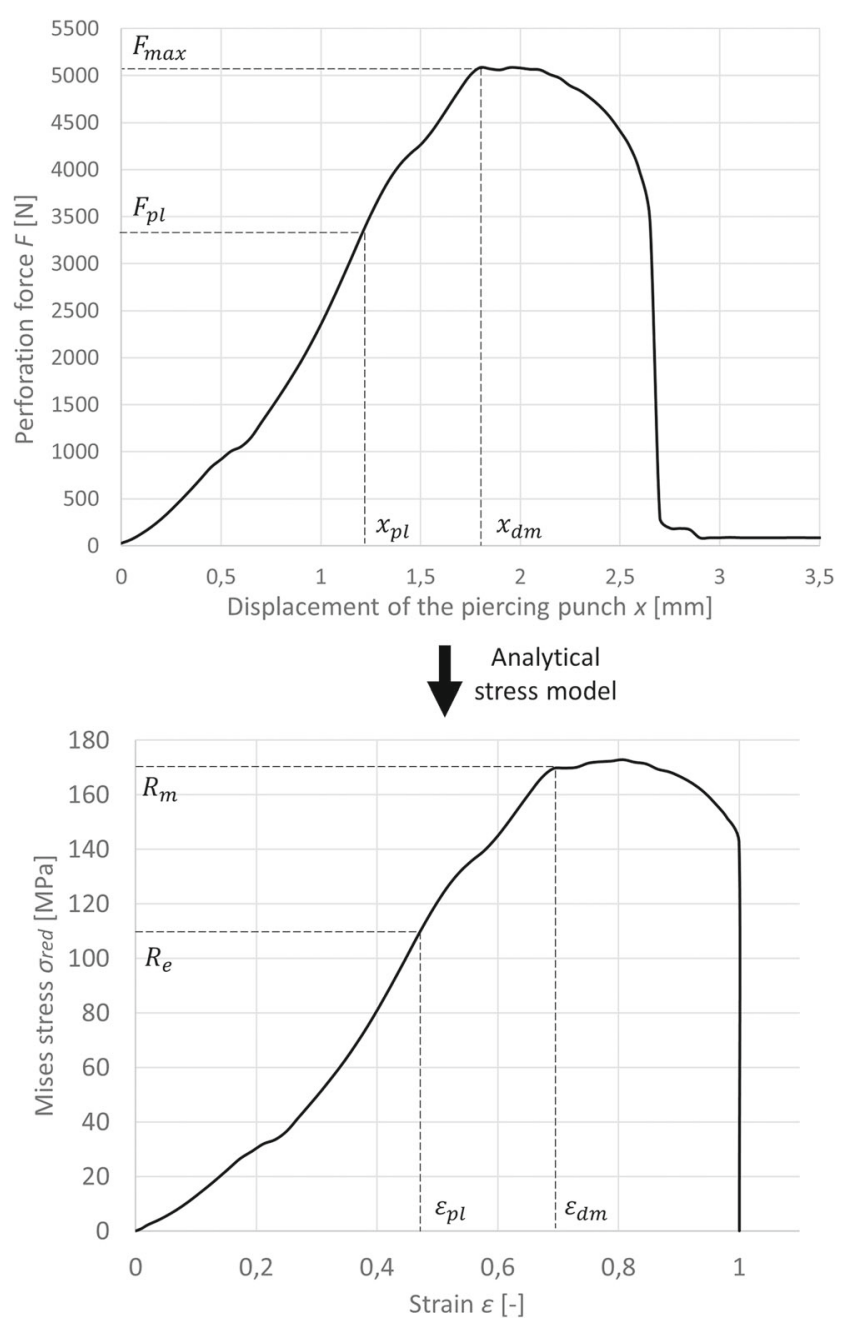

Fig. 15 Force characteristic in TFL10S belt perforation process along with stress-strain curve obtained with proposed model

is worth mentioning that the manufacturers do not give the specific value but only the range in which the value lays. Additionally, along the cross section of the belt the friction coefficient will change, so it is safe to assume the coefficient for rubber covers, which is the highest value among the parameters for all the materials which the belt consists of and which has a contact with tools during entire perforation process.

Table 2 Parameters needed for force estimation

\begin{tabular}{lllll}
\hline $\begin{array}{l}\text { Type } \\
\text { of belt }\end{array}$ & $\begin{array}{l}\xi_{c r} \\
{[-]}\end{array}$ & $\begin{array}{l}E / g \\
{[\mathrm{MPa} / \mathrm{mm}]}\end{array}$ & $\begin{array}{l}\epsilon_{d m} \\
{[-]}\end{array}$ & $\begin{array}{l}g / g_{P A} \\
{[-]}\end{array}$ \\
\hline M500 & 0.75 & 80.4 & 0.76 & 5 \\
TFL7S & 0.76 & 92.5 & 0.708 & 3.43 \\
TFL10S & 0.74 & 90 & 0.692 & 2.6 \\
TFL15S & 0.69 & 93 & 0.661 & 2.07 \\
\hline
\end{tabular}

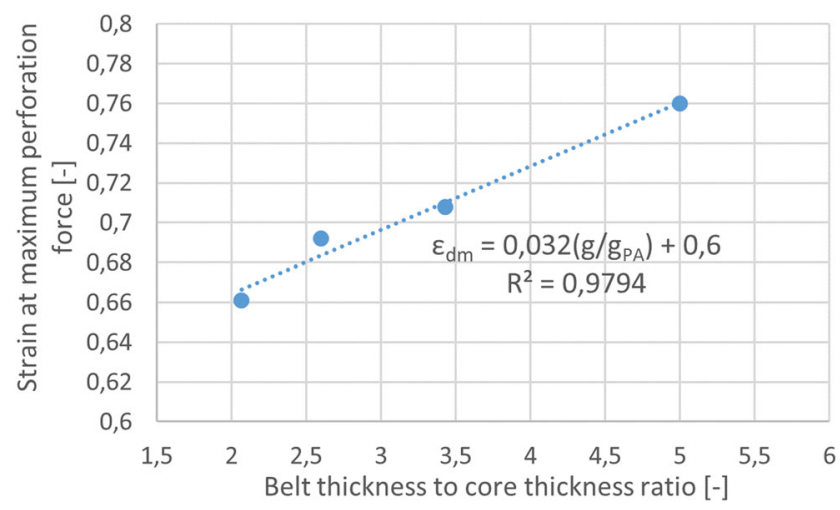

Fig. 16 Strain at maximum perforation force in function of belt thickness to polyamide core thickness ratio

In Fig. 15, the characteristic of perforation force in function of displacement of the piercing punch for the belt TFL10S was presented along with the stress-strain curve obtained by using the acquired empirical data in the proposed analytical model. Points which correspond with the values obtained from the uniaxial tensile test (yield point and tensile strength) were marked on the stress-strain curve. For these stress values, corresponding strains can be read from the characteristics and interpreted as strains at which the plastic deformation or damage occurs. In order to calculate the estimated value of the peak force, we need to calculate the displacements: $x_{p l}$-where the plastic softening starts—and $x_{d m}$-where the cracking occurs-by using equations:

$x_{p l}=\frac{R_{e}}{E} g, x_{d m}=\epsilon_{d m} \cdot g$

In the applied methodology, the authors assumed that peak stress value should equal the ultimate tensile strength of the belt. The fundamentals of this assumption is the

Table 3 Compression area factors in function of friction coefficient

\begin{tabular}{|c|c|c|c|c|}
\hline \multirow[b]{2}{*}{$\mu[-]$} & \multicolumn{4}{|l|}{$\xi$ factor } \\
\hline & M500 & TFL7S & TFL10S & TFL15S \\
\hline 0.5 & 0.715 & 0.8501 & 0.8394 & 0.8665 \\
\hline 0.51 & 0.722 & 0.8528 & 0.8422 & 0.8686 \\
\hline 0.52 & 0.73 & 0.8554 & 0.8451 & 0.8707 \\
\hline 0.53 & 0.738 & 0.8581 & 0.848 & 0.8728 \\
\hline 0.54 & 0.745 & 0.8608 & 0.8509 & 0.875 \\
\hline 0.55 & 0.752 & 0.8635 & 0.8538 & 0.8772 \\
\hline 0.56 & 0.759 & 0.8663 & 0.8567 & 0.8794 \\
\hline 0.57 & 0.766 & 0.869 & 0.8596 & 0.8816 \\
\hline 0.58 & 0.773 & 0.8718 & 0.8626 & 0.8839 \\
\hline 0.59 & 0.779 & 0.8745 & 0.8656 & 0.8862 \\
\hline 0.60 & 0.7859 & 0.8773 & 0.8685 & 0.8885 \\
\hline
\end{tabular}


Fig. 17 Compression area factor in function of Young's modulus to belt thickness ratio

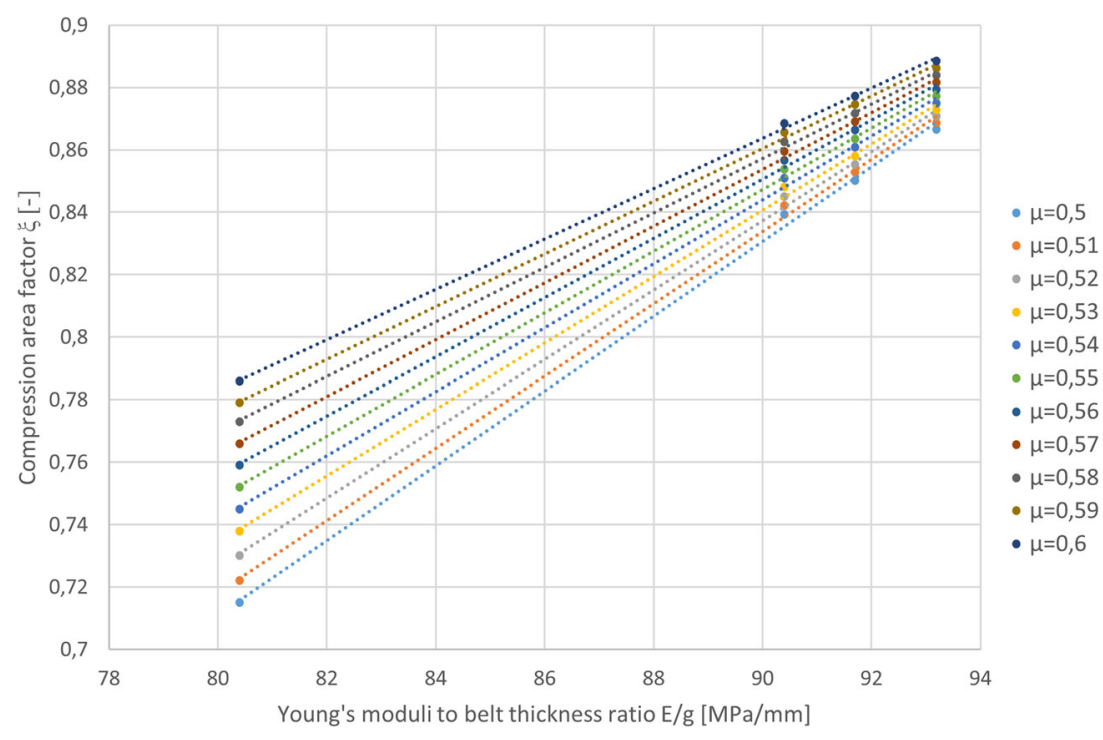

In order to fulfill the assumption that the peak stress in the perforation process equals the tensile strength of the belt, for all 4 tested belts (M500, TFL7S, TFL10S, and TFL15S), proper compression area factor $\xi$ was calculated. Due to the strong dependence of the friction coefficient on the perforation force and its undefined value, it was necessary to test the whole range of variable. Results of this analysis are presented in Table 3. As proposed in Section 3, a linear dependence between the coefficient $\xi$ and Young's modulus to belt thickness ratio $E / g$ was found. Derived correlations are presented as a set of curves in Fig. 17 and their equations are presented in Table 4.

As can be seen in the Fig. 17, the convergence of model is increased with increasing the stifness of the belt. The reason for losing the accuracy of the model for a more elastic belt with lower Young's moduli to belt thickness ratio is not considering the geometrical limits of the belt in the model. Assuming that the angle of deformation cannot be higher than $45^{\circ}$ and knowing that there are two almost symmetrical cutting edges on both sides of the belt, which are compressed into the belt, the distance of the belt in which the compression of the scrap occurs can be limited with the following inequality:

$a \leq \frac{g}{2}$

Table 5 Parameters needed for force approximation

\begin{tabular}{llllllll}
\hline $\begin{array}{l}\text { Type } \\
\text { of belt }\end{array}$ & $\begin{array}{l}x_{p l} \\
{[\mathrm{~mm}]}\end{array}$ & $\begin{array}{l}F_{p l} \\
{[\mathrm{~N}]}\end{array}$ & $\begin{array}{l}x_{d m} \\
{[\mathrm{~mm}]}\end{array}$ & $\begin{array}{l}F_{\text {Amax }} \\
{[\mathrm{N}]}\end{array}$ & $\begin{array}{l}k \\
{\left[\frac{N}{m m}\right]}\end{array}$ & $\begin{array}{l}b \\
{\left[\frac{\mathrm{Ns}}{m m}\right]}\end{array}$ & $\begin{array}{l}F_{\text {Rmax }} \\
{[\mathrm{N}]}\end{array}$ \\
\hline M500 & 0.71 & 2438 & 1.9 & 3685 & 3439 & 2494 & 3563 \\
TFL7S & 1.07 & 2869 & 1.7 & 4234 & 2684 & 2730 & 4154 \\
TFL10S & 1.22 & 3458 & 1.78 & 5274 & 2841 & 3623 & 5223 \\
TFL15S & 1.16 & 2908 & 2.06 & 5924 & 2510 & 6032 & 5924 \\
\hline
\end{tabular}


Fig. 18 Comparison analytical and empirical characteristic of perforation force in function of the piercing punch displacement - TFL10S

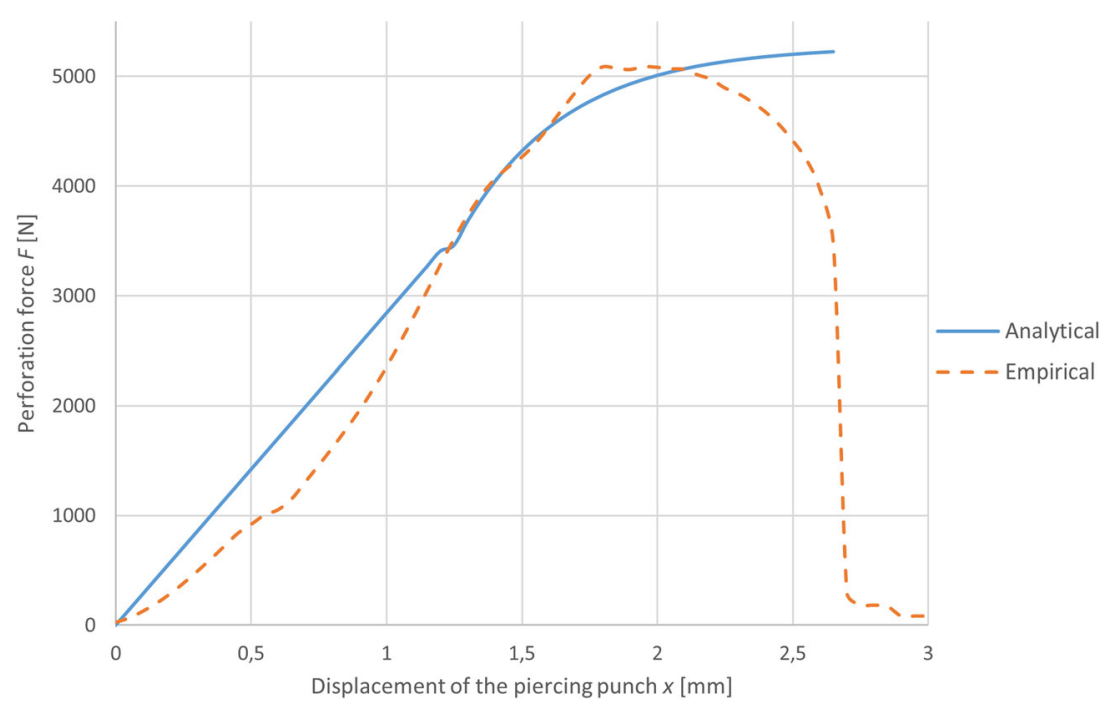

If we determine the distance $a$ using compression area factor $\xi$, we can derive its critical value-for analyzed belts these values are presesnted in Table 2 .

$(1-\xi) \leq \frac{g}{2} \rightarrow \xi_{c r}=1-\frac{g}{2 R}$

The upper limit can be considered for rigid belts. Belt TFL15S can be treated as a ideal rigid belt due to the deflection of the belt during perforation is smaller than the displacement of the punch, so the whole front surface of the punch has contact with belt during the entire process. For that reason the value $\xi=0.888$, obtained for the highest possible friction coefficient $\mu=0.6$, can be considered as an upper limit for a compression area factor. Increasing the $\xi$ factor with increasing the frictional drag between belt and the die can be explained with more difficult compression of the scrap inside the die channel, which will reduce the angle of deformation and as a result the distance at which the scrap is compressed.

Based on that analysis, for a belts which are not in the range of presented model, one of the limit values should be taken into consideration during the estimation of the perforation force and the corresponding friction coefficient (lowest or highest) should be used.

Taking into consideration derived parameters, we can use the inverted model (33) to calculate $F_{p l}$ and $F_{A \max }$ by substituting the $R_{e}$ and $R_{m}$ as a equivalent stress $\sigma_{e q v}$. Results are presented in Table 5.

Presented methodology makes it possible to check only the peak force value, which makes it very useful in the punching die design process. However, if we need to estimate the whole characteristic of the force in the elasticplastic range, we can use the rheological model proposed in Section 3. Based on the previous calculations, we can derive the parameters of this model (5) with the following equations:

$k=\frac{F_{p l}}{x_{p l}}, b=\frac{F_{A \max }-F_{p l}}{v_{0}}$

In order to validate the proposed methodology the comparison of the analytical (rheological) $F_{R}$ and empirical force $F_{E}$ characteristics for belt TFL10S is presented in Fig. 18. The error analysis of the peak values for both methods is shown in Table 6 and it do not exceed 4\%, however, in order to confirm the compatibility of the model in the whole range of polyamide core composite belts, it is necessary to widen the spectrum of specimen used in the test.

\section{Validation of the analytical model with using FEM analyses}

In order to verify the proposed model following methodology was used:

- empirical test of punching the TFL10S belt was performed and its result was recorded as a force characteristic in function of the piercing punch displacement,

Table 6 Parameters needed for force approximation

\begin{tabular}{llllll}
\hline $\begin{array}{l}\text { Type } \\
\text { of belt }\end{array}$ & $\begin{array}{l}F_{\text {Emax }} \\
{[\mathrm{N}]}\end{array}$ & $\begin{array}{l}F_{\text {Amax }} \\
{[\mathrm{N}]}\end{array}$ & $\begin{array}{l}F_{\text {Rmax }} \\
{[\mathrm{N}]}\end{array}$ & $\begin{array}{l}e_{A} \\
{[\%]}\end{array}$ & $\begin{array}{l}e_{R} \\
{[\%]}\end{array}$ \\
\hline M500 & 3538 & 3685 & 3563 & 4.15 & 0.71 \\
TFL7S & 4143 & 4234 & 4154 & 2.20 & 0.27 \\
TFL10S & 5085 & 5274 & 5223 & 3.72 & 2.71 \\
TFL15S & 6168 & 5924 & 5924 & 3.96 & 3.96 \\
\hline
\end{tabular}


Fig. 19 FEM ABAQUS model used in the analysis

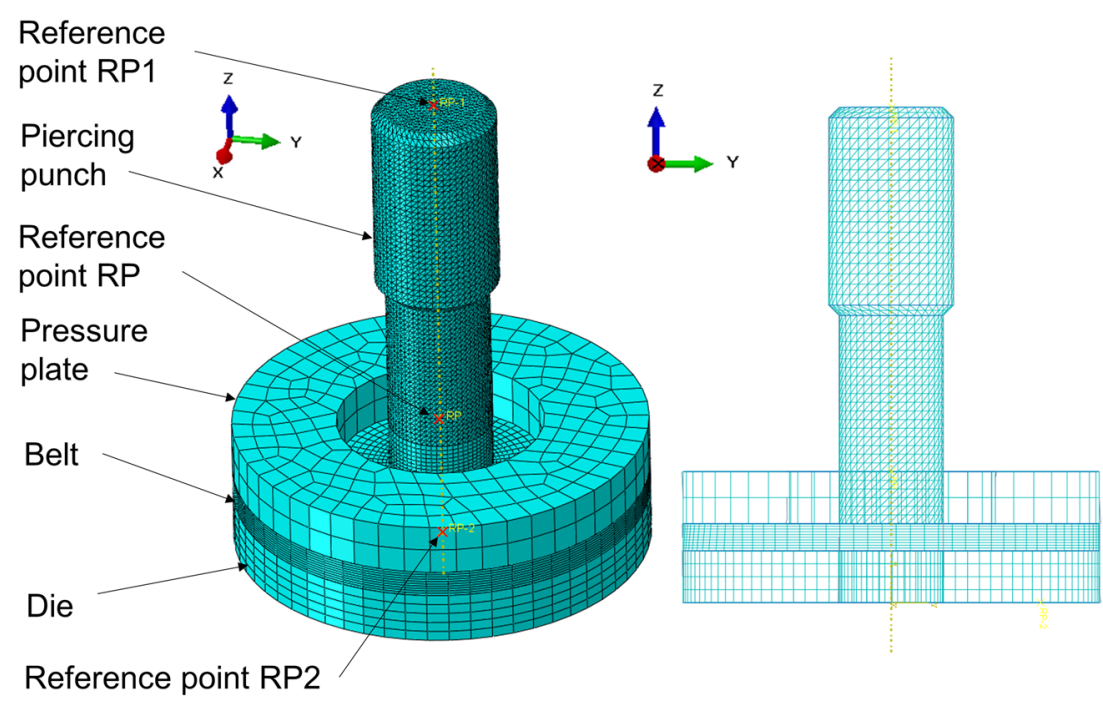

- obtained characteristic was substituted into the analytical stress model in order to get stress-strain curve,

- from the stress-strain curve, necessary mechanical properties and parameters of Johnson-Cook damage model was calculated,

- FEM model in ABAQUS was created with previously calculated values and the reaction force in function of displacement was measured,

- both FEM and empirical tests results were compared and the error was determined.

The construction of FEM model in ABAQUS/Explicit was presented in Fig. 19. The assembly consists of four instances: the piercing punch, die, belt, and blank holder. Beside the belt, all the instances were made of steel and modelled as rigid bodies using a proper constrain between an instance and one of the reference points. The pressure plate was tied with the reference point RP and the die was constrained with RP2. Both points were fixed with ENCASTRE boundary condition, which blocked all the degrees of freedom. The piercing punch was connected with RP1 point and in order to extort its movement of the velocity, the boundary condition was applied to the reference point. This $\mathrm{BC}$ sets $\mathrm{V} 3$ value as $-0.0005 \mathrm{~m} / \mathrm{s}$ and resets other linear or angular velocities as 0 , leaving only one active degree of freedom. The belt was modelled as a deformable part and its general and elastic parameters were defined according to the Table 7. Plastic properties of the

Table 7 Parameters used in the FEM analysis

\begin{tabular}{llllll}
\hline$\rho$ & $E$ & $v$ & $d_{1}$ & $d_{2}$ & $d_{3}$ \\
{$\left[\mathrm{~kg} / \mathrm{m}^{3}\right]$} & {$[\mathrm{MPa}]$} & {$[-]$} & {$[-]$} & {$[-]$} \\
\hline 1140 & 310 & 0.2 & -0.24 & 0.32 & 2.6 \\
\hline
\end{tabular}

material were assumed as isotropic and were obtained as tabular values from the stress-strain curve, where plastic strain 0 occurs at $112 \mathrm{MPa}$. The damage of the material was modelled with the simplified Johnson-Cook model $[31,43,44]$, where the deformation rate and temperature are insignificant ( $d_{4}$ and $d_{5}$ equal 0 ). The remaining $\mathrm{J}$ $\mathrm{C}$ parameters are shown in Table 7. Damage evolution was specified by the displacement at failure parameter and equals 0 . The interaction in the model was made as a general contact and its properties were defined with tangential behavior friction coefficient 0.6 and normal behavior of "Hard" contact. Beside the piercing punch, all the instances were meshed with hexahedral, 3D stress, linear C3D8R explicit elements. The belt was divided for partition that both cutting edges has a contact with the same element. The cutting edges along were divided for 30 elements on its circumference. Due to the complex geometry, the grip part of the punch was meshed with tetrahedral C3D10M elements. Mesh control used in the model makes it possible to obtain 10 elements on the thickness belt of size $0.00026 \mathrm{~m}$ each and dense the mesh in region near the shear cross section. In the case of the belt instance, the element deletion was enabled and the field output with STATUS variable was added. The results were taken from the history output for RP1 point, which saved the RF3 reaction force. The time period of the analysis was $10 \mathrm{~s}$. In order to reduce the computational time, a mass scaling was used with target time increment 0.001 . It was possible due to the quasi-static character of the test and low velocity.

The results of the performed FEM analysis are presented as a stress distribution in two different stages of punching: plastic flow (Fig. 20) and failure and scrap separation (Fig. 21). Comparison of the obtained perforation force characteristic for FEM and empirical tests is shown in Fig. 22. 

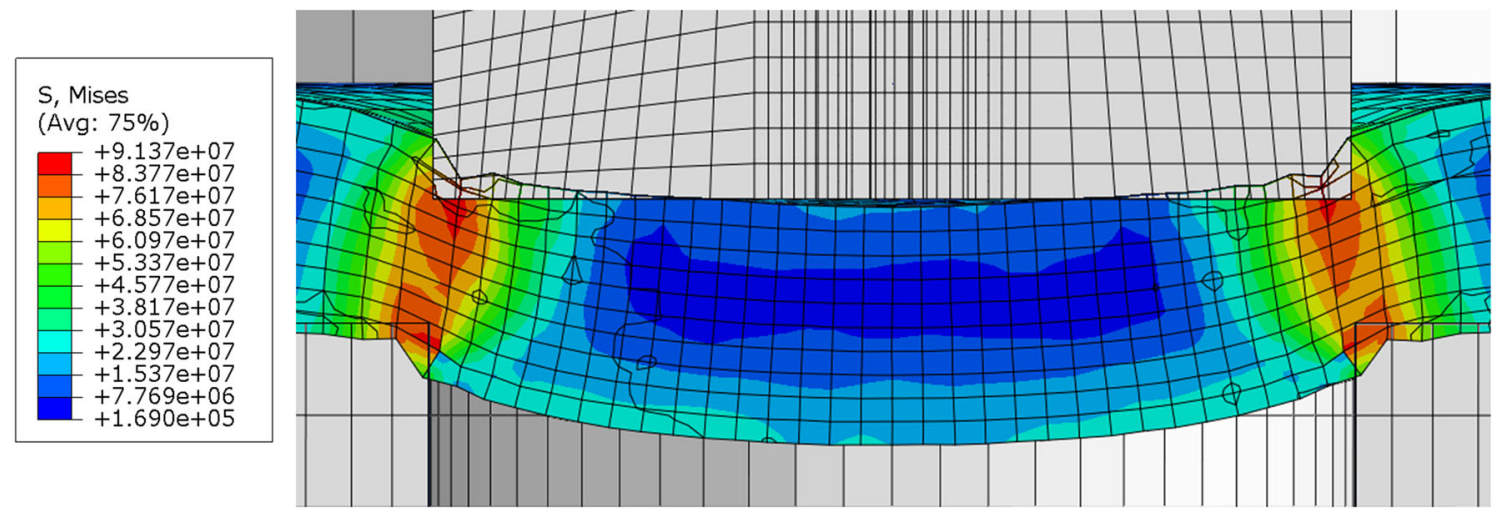

Fig. 20 Stress distribution in belt punching-FEM analysis results
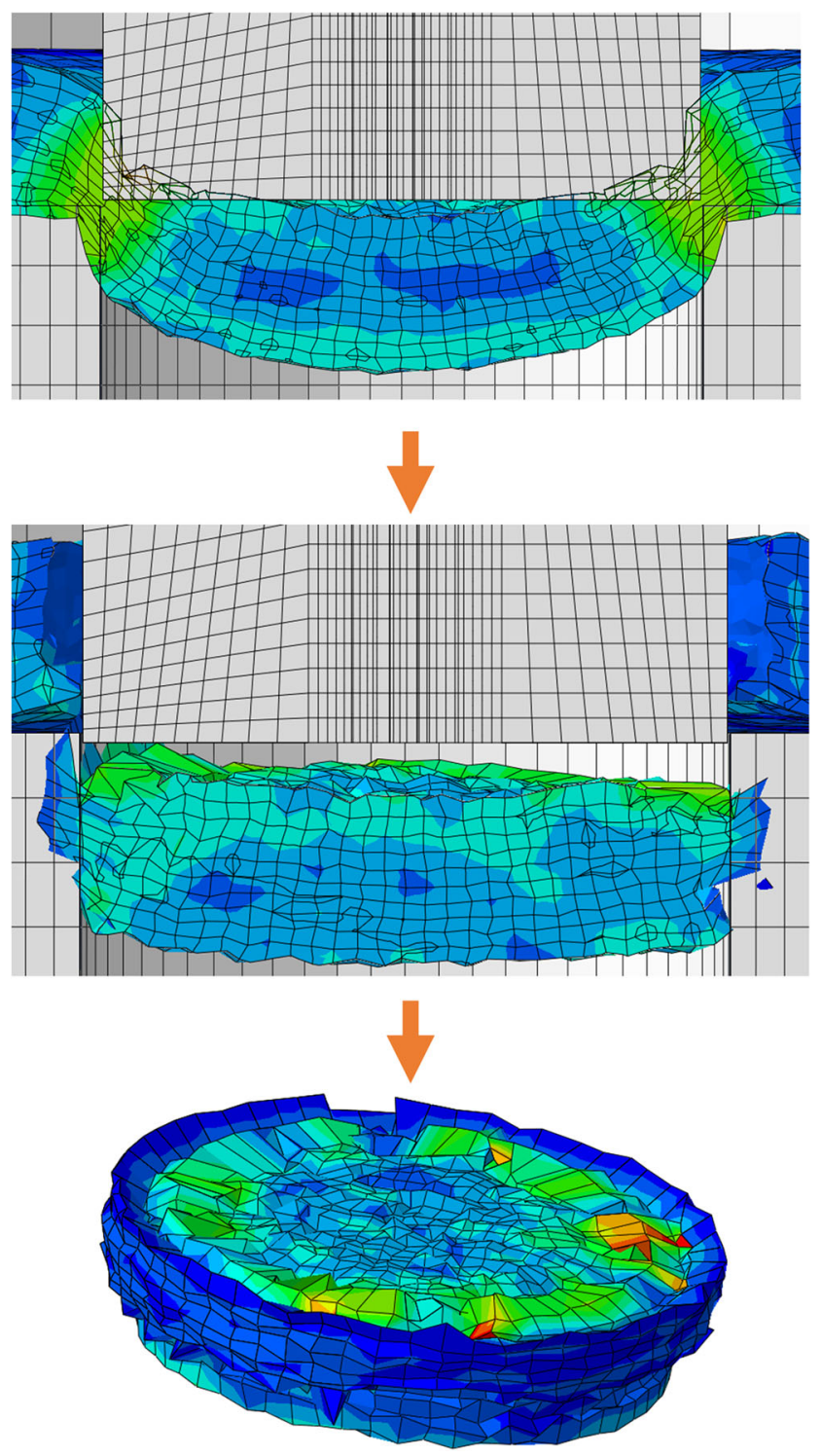

Fig. 21 Final stage of the belt punching process - failure and the scrap separation - FEM analysis results
The error obtained from the model validation in some point exceeds $20 \%$, however the peak value of the force is almost the same as the empirical one. This means that using that approach may not be effective to estimate the force characteristic, but can be easily used to estimate its peak value. The reason of the inaccuracy is the accumulation of errors due to using the analytical model in order to determine the parameters for FEM analysis. The meshing of the model has the main influence on the obtained error, which also has an effect on the damage initiation and evolution parameters.

Another reason of the inaccuracy is considering the composite material to be equivalent homogenous one [45]. However, it was proven that machining simulations for composites can be made based on an equivalent homogenized modeling [46]. There are multiple examples of simplifying the anisotropic materials, like natural composites (wood, bamboo) or engineering composites (fiber reinforced polymer composites or metal matrix composites), with using either orthotropic or transversly isotropic model can be found [33, 34, 45-51]. Successful modelling of the plasticity for the composite material with J-C model, which is an isotropic approach, can also be found [50,51]. Additionally, the brittle reinforcement materials are usually modelled as lineary elastic material with damage initiation being instaneous hence, the lack of damage evolution law. It is assumed that the material fracture occurs at a stress level, which corresponds with an ultimate tensile strength [46]. Since the core of the belt made of polyurethene has a tendency for a brittle fracture and provides the main strength of the multilayer structure, using an isotropic approach for that type of structure should provide adequate results.

All of that caused a relatively high error. However, for a comparative analysis this is acceptable and will enable the model to be useful in searching the effective geometry of the piercing punch for polymer composite belts. 
Fig. 22 Comparison of the perforation force characteristics obtained by empirical and FEM tests

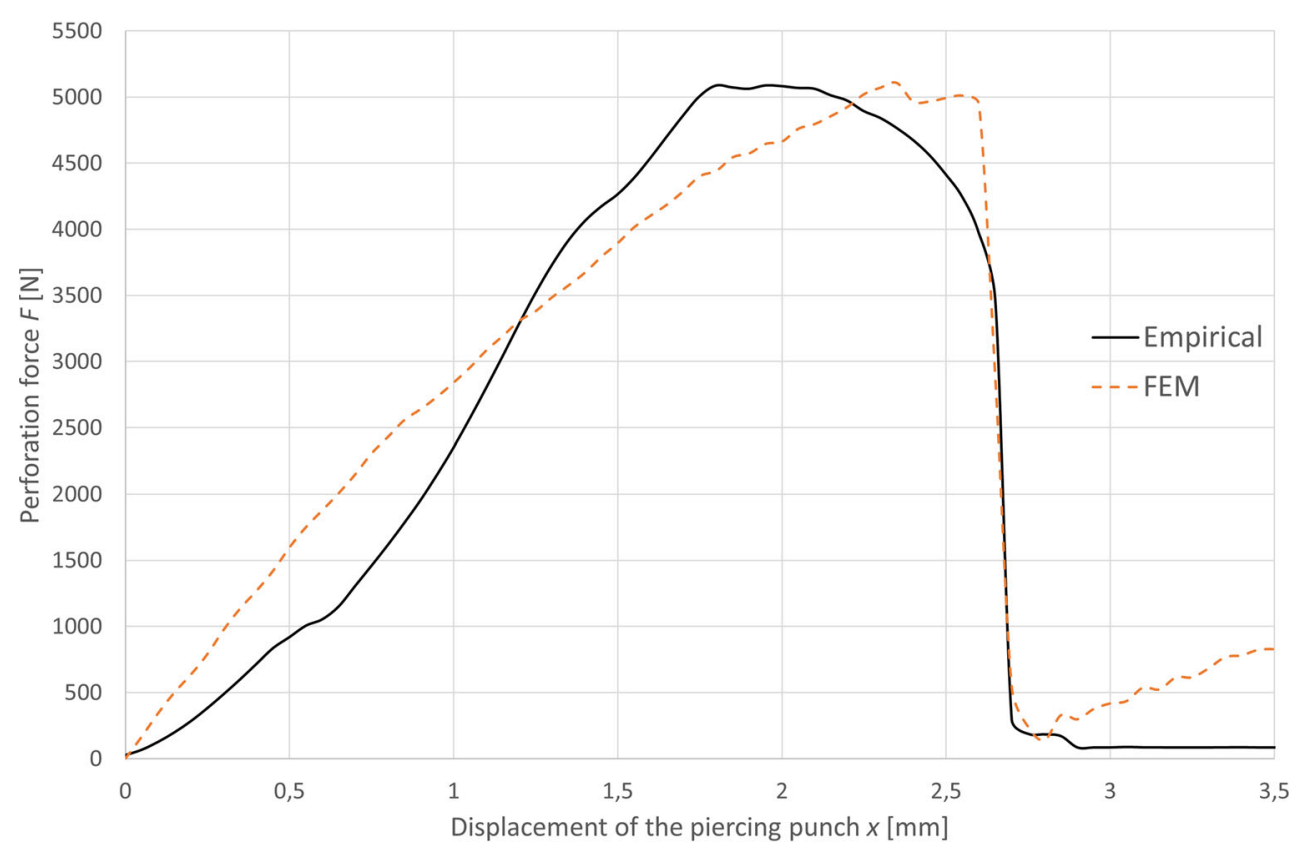

\section{Determining the shape factors for selected piercing punches profiles}

In order to determine the influence of the punch shape on the perforation force maximum value and its characteristics, a series of tests were performed for 8 selected geometries of the piercing punches and 10 different types of belts. To maintain order in the presented results, the following legend (Table 8) was used to mark the specimen. All the data acquired from the tests was gathered and presented in Table 9, where the force reduction was highlighted with italic. Aside of the peak value of the perforation force, its characteristic also has an influence on the efficiency of the process. In order to fulfil the complex comparative analysis of a various piercing punch shape effect, the characteristics for the belt TFL10S and all the punches used in the tests

Table 8 Symbol definition used in results presentation

\begin{tabular}{ll}
\hline Symbol & Type of punch \\
\hline PD & Flat piercing punch \\
PDCB & Punch with cylindrical bowl \\
PDDS & Double sheared (inverted chamfered) punch \\
PDC & Chamfered flat punch \\
PDCP & Punch with conical pilot \\
PDSB & Punch with spherical bowl \\
PDSS & Single sheared punch \\
PDV & V-shaped chamfered punch \\
\hline
\end{tabular}

are presented in Fig. 23. As can be observed, only two punch profiles (flat chamfered and the one with conical pilot) had increased the force necessary to perform the punching process. Based on that, flat chamfered and conical punches were defined as non-effective ones and excluded from the further research. The lowest force was used with the single sheared punch, however, the displacement needed to separate the belt from the base material was almost three times higher than the thickness of the belt. This implicates that using this type of tool requires having a larger stroke of the punching cylinder or press than for a standard tool. Additionally, an important disadvantage was shown in the test for the TFL15S belt. During the test there was a collision between the punch and the die, which causes the damage of both cutting edges. The reason for that is the presence of a large lateral force in the perforation process due to the asymmetry of the piercing punch. It is a huge problem especially in the belt perforation, where the clearance is really small. For thin and elastic belts the value of this force is rather small, which makes it insignificant for the deflection of the punch. But for the rigid belt it makes the punch useless. Based on that, this type of punch was also excluded from further research.

Besides, force value also hole precision should be considered in finding the effective geometry of the piercing punch. For all the belts, the best hole precision was achieved for the piercing punch with a spherical bowl. Both PDCB and PDDS punches had an acceptable precision, however, to the axial asymmetry slight ovality of the holes can be observed. On the other hand, the V-shape punch did not cut 
Table 9 Peak perforation force for selected punch profiles and different types of belts-results of empirical research

\begin{tabular}{|c|c|c|c|c|c|c|c|c|}
\hline $\begin{array}{l}\text { Peak perforation } \\
\text { force } F_{E \max }[\mathrm{N}]\end{array}$ & PD & PDCB & PDDS & PDC & PDCP & PDSB & PDSS & PDV \\
\hline SG500 & 2713 & 820 & 1207 & 3444 & 3280 & 1136 & 805 & 1991 \\
\hline TTA500N & 3191 & 980 & 1370 & 3640 & 3526 & 1181 & 876 & 2191 \\
\hline TTA1000N & 4401 & 1648 & 2493 & 4883 & 4667 & 1780 & 1390 & 3608 \\
\hline M500 & 3538 & 1344 & 1998 & 4627 & 4270 & 1413 & 1453 & 3259 \\
\hline TFL7S & 4143 & 1652 & 2539 & 4796 & 4644 & 1682 & 1408 & 3514 \\
\hline TFL10S & 5086 & 2568 & 3507 & 5570 & 5606 & 2138 & 1847 & 4471 \\
\hline TFL15S & 6168 & 3695 & 4427 & 6960 & 6800 & 2810 & - & 5882 \\
\hline XH500-6 & 3471 & 3068 & 3530 & 3992 & 3836 & 3677 & 1680 & 3704 \\
\hline LAB12E & 2100 & 739 & 1161 & 2894 & 2562 & 840 & 757 & 1768 \\
\hline $\mathrm{T} 10 \mathrm{~K}$ & 2006 & 1043 & 1398 & 2638 & 2314 & 1003 & 811 & 1747 \\
\hline
\end{tabular}

Fig. 23 Comparison analytical and empirical characteristic of perforation force in function of the piercing punch displacement for various punch shapes

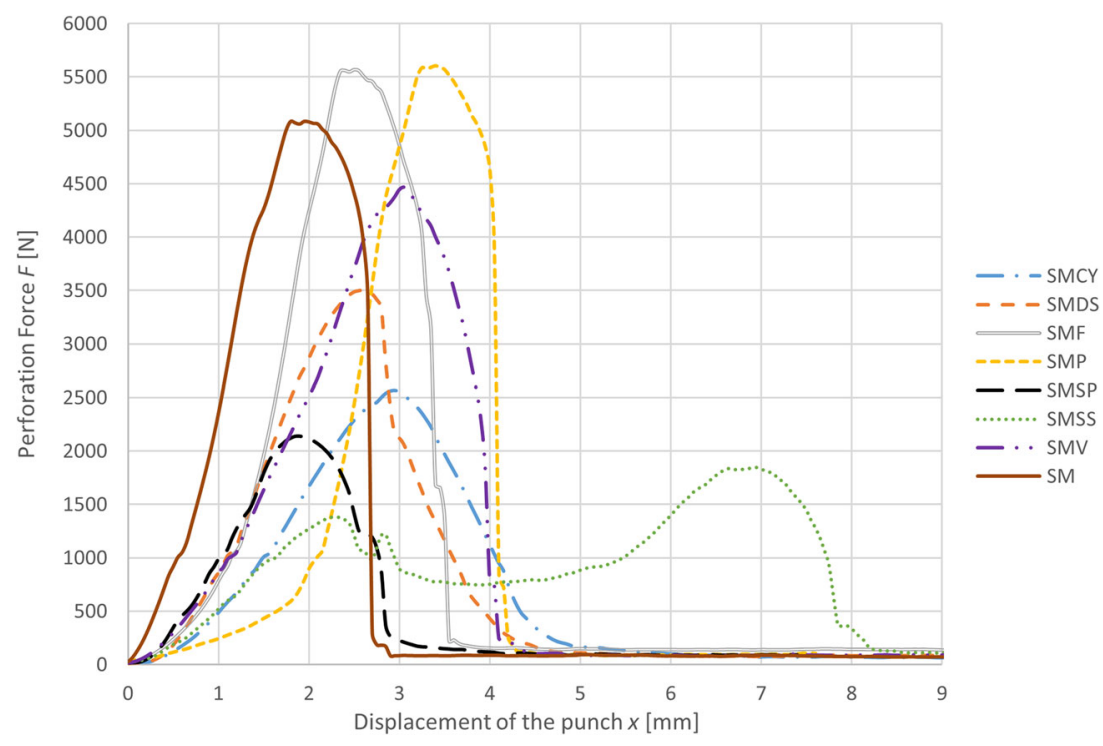

Fig. 24 Comparison analytical and empirical characteristic of perforation force in function of the piercing punch displacement - TFL10S

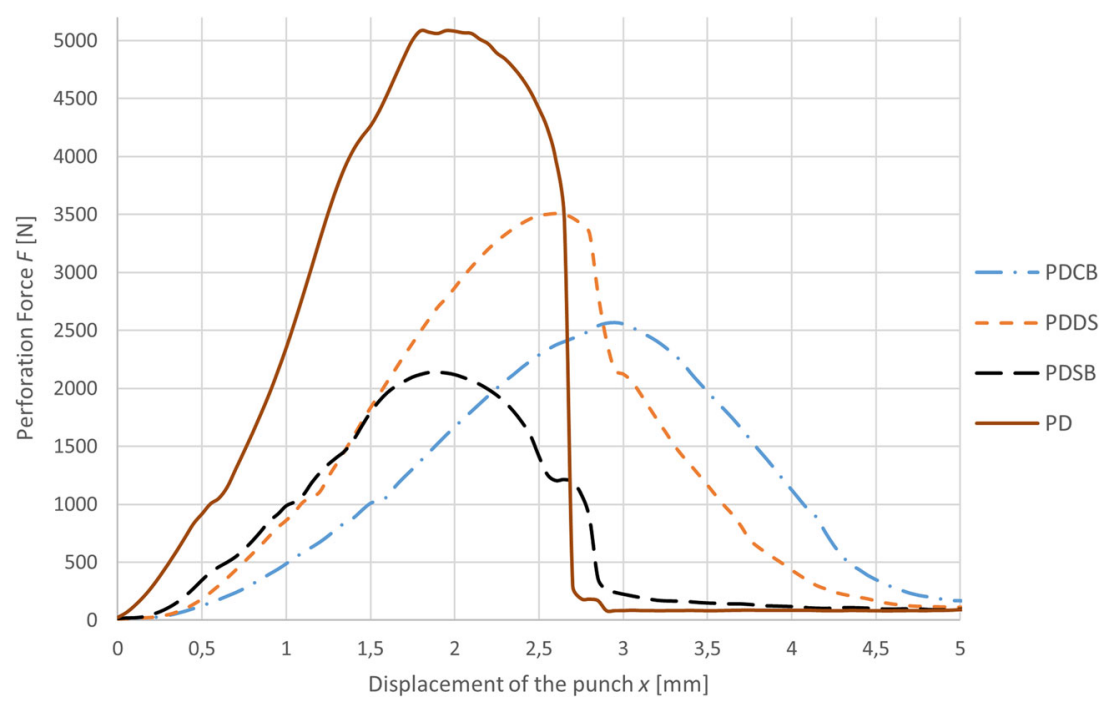


Fig. 25 Comparison of the perforation force characteristics for different punch profiles-T10K belt

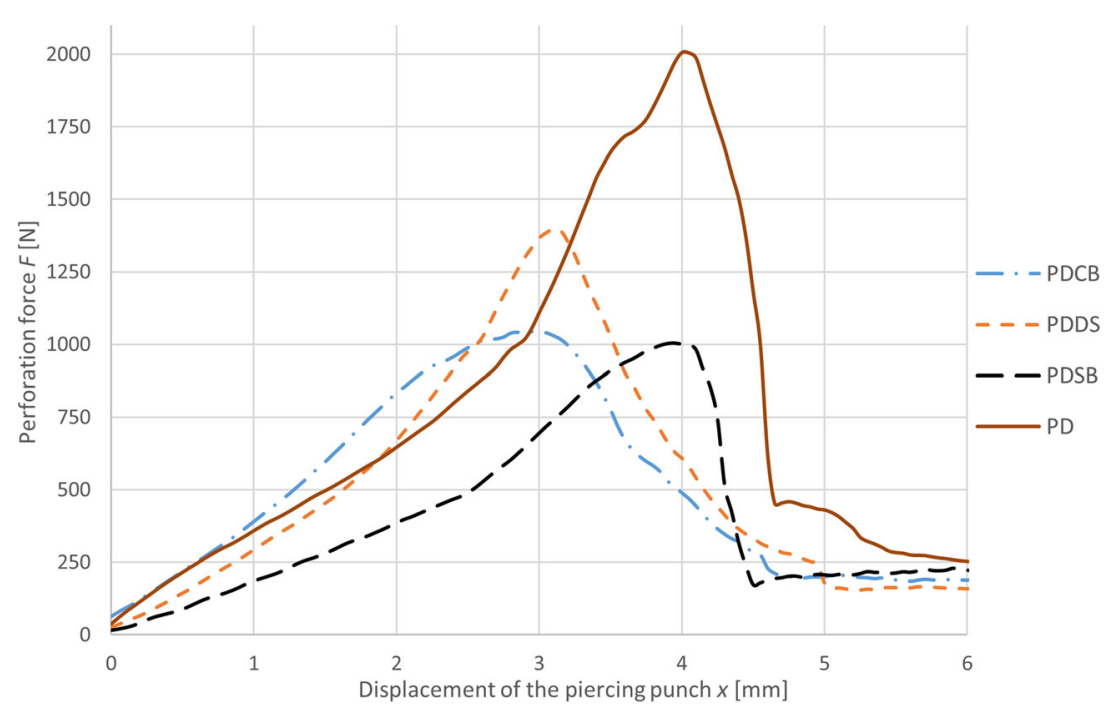

all the fibers and fabrics entirely, and based on that, this punch was also excluded from further research.

If we analyze the results for the thickest belt XH5006 , we can observe that almost all the punch modifications caused an increase of the perforation force. This may be caused by the fact that all the bowls and inverted chamfering made in the punches has a depth lower than the thickness of the belt $(6 \mathrm{~mm})$. Because of that, sharp edges penetrate only part of the material and after that material is tried to be pressed with only one active cutting edge of the die. This indicates that in order to develop this type of piercing punches it is necessary to perform full analysis of the geometrical features like angles and radiuses on the perforation force for a wide spectrum of belts.

For the analysis of the force characteristic for various groups of polymer composite belts, three characteristics (one per the representative of each group) are presented in Figs. 24, 25, and 26. For a rigid belt with polyamide core (Fig. 24) slight offset from the flat punch characteristic can be observed in all types of punches beside the piercing punch with a spherical bowl. Although increasing the stroke may cause a longer cycle time for one hole, it may also have a positive effect in a limited range by eliminating the sudden force drop as observed in the characteristics for the punch with a cylindrical bowl and double sheared one. The most beneficial punch profile for this type of belts is the punch with a spherical bowl. The force is reduced by approximately $60 \%$, the displacement does not exceed the thickness of the belt and the force drop is much more gentle than for a flat punch.

The main difference between rigid belts and other groups of belts is that the failure of the material occurs almost immediately after the force reaches its peak value. This means that the plastic flow phase is not so visible due to the fact that the main strength of these belts are fibers or fabrics. In the case of the aramid fiber reinforced polyurethane
Fig. 26 Comparison of the perforation force characteristics for different punch profiles LAB12E belt

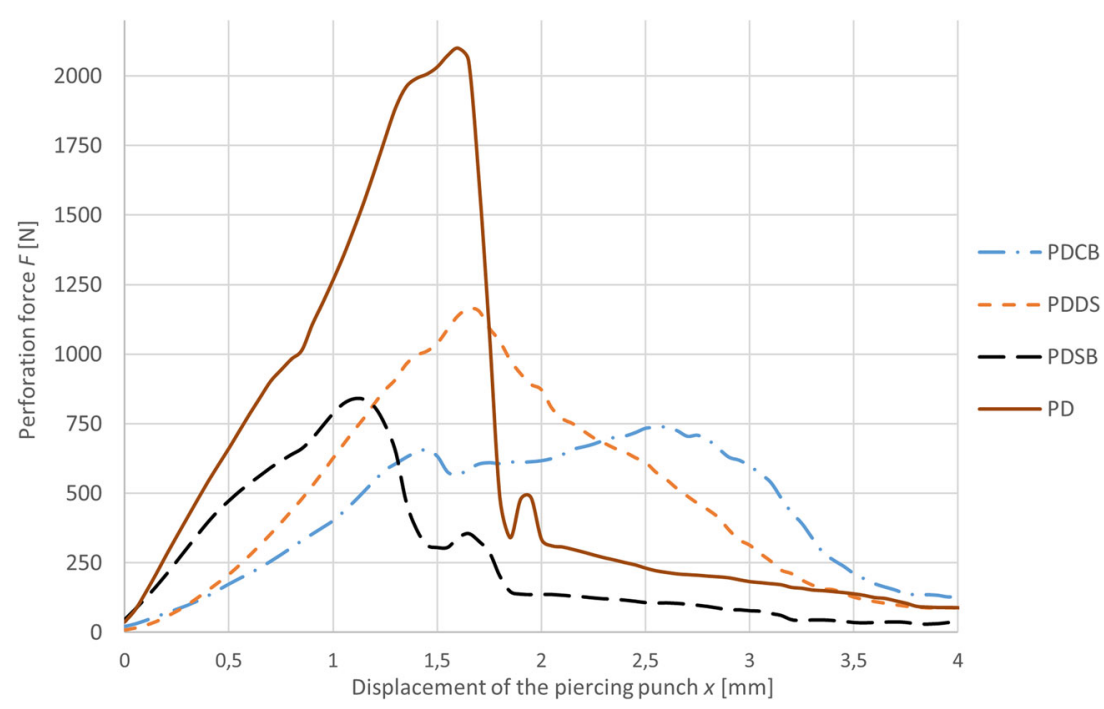


Table 10 Shape factor for selected punch profiles and different types of belts-results of empirical research

\begin{tabular}{llll}
\hline $\begin{array}{l}\text { Shape factor } \\
\beta[-]\end{array}$ & PDCB & PDDS & PDSB \\
\hline SG500 & 0.3 & 0.44 & 0.42 \\
TTA500N & 0.31 & 0.43 & 0.37 \\
TTA1000N & 0.37 & 0.57 & 0.4 \\
M500 & 0.38 & 0.56 & 0.4 \\
TFL7S & 0.4 & 0.61 & 0.41 \\
TFL10S & 0.5 & 0.69 & 0.42 \\
TFL15S & 0.6 & 0.72 & 0.46 \\
XH500-6 & 0.88 & 1.02 & 1.11 \\
LAB12E & 0.35 & 0.55 & 0.4 \\
T10K & 0.52 & 0.7 & 0.5 \\
\hline
\end{tabular}

toothed belt (Fig. 25) the force reduction is similar as in the polyamide core belt. Positive effects can be observed for the punch with a cylindrical bowl (PDCB) and a double sheared punch (PDDS) because despite softening the force drop there is no offset from the PD characteristic. For the spherical bowl punch, the force drop is more sudden, however, due to the low value of perforation force (about $1 \mathrm{kN}$ ), it is not significant from the point of loading the punching die. For the elastic belt with polyurethane core reinforced with polyester fabric (Fig. 26), lower force is achieved by using a cylindrical instead of spherical bowl punch, but it causes the increase of its displacement in the perforation process. This observation can be explained by analyzing the mechanical behaviour of the LAB12E belt. In this case after cutting through the polyester fabric, the belt loses almost entire strength. Because the depth of the bowl is higher in PDCB tool than in PDSB, before the contact between the belt surface and inner surface of the cylindrcal bowl occurs, the fabric is already cut. This indicates that the resistance of the belt is decreased and as a result the perforation force is lower than the one obtained for a punch with a spherical bowl.

For the remaining three punch profiles (PDCB, PDDS, and PDSB), the authors decided to calculate the shape factors $\beta$ (according to the Eq. 42), which were shown in Table 10. In order to use obtained values for a perforation force estimation, a model for approximating its value was also derived.

$\beta=\frac{F_{S M i}}{F_{S M}}$

where $F_{S M i}$-peak perforation force for selected piercing punch profile [N], $F_{S M}$-peak perforation force for basic flat punch $[\mathrm{N}]$.

In the case of the spherical bowl punch, the value of the shape factor fluctuates around 0.4. Only for thicker belts (TFL15S, XH500-6, and T10K) the value is higher, because their thickness is higher than bowl depth. It is safe to assume that for belts with thickness lower than the depth of the bowl the shape factor $\beta$ equals 0.4. For other two punch profiles, the proper characteristics are derived and presented in Fig. 27. The authors noticed that the shape factor depends on the product of peak force value for the flat punch and belt thickness, which can be described as a mechanical cutting work.

The abovementioned analysis of the shape factors can be combined with the model for estimating the force for the flat punch and as a result gives us an estimated value of the
Fig. 27 Shape factor in function of peak force for flat punch $\mathrm{F}_{\mathrm{SM}}$ and belt thickness $g$

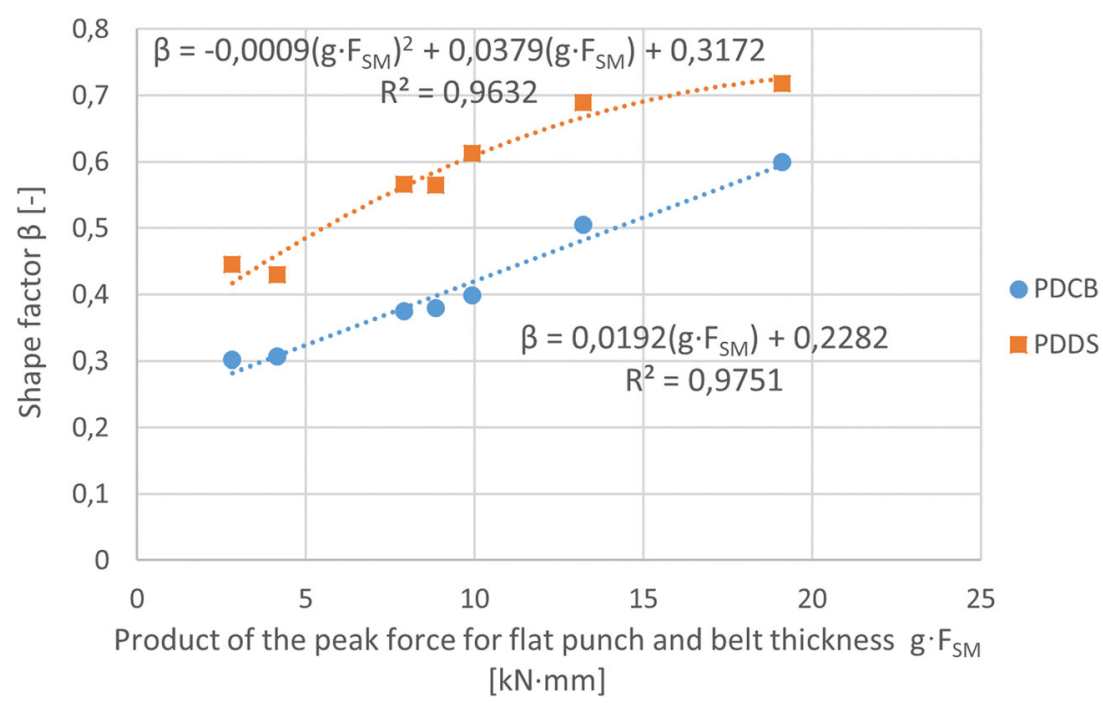


Table 11 Mechanical properties of the belts used for veryfication of the model

\begin{tabular}{llllllll}
\hline $\begin{array}{l}\text { Type } \\
\text { of belt }\end{array}$ & $\begin{array}{l}g \\
{[\mathrm{~mm}]}\end{array}$ & $\begin{array}{l}g_{P A} \\
{[\mathrm{~mm}]}\end{array}$ & $\begin{array}{l}E \\
{[\mathrm{MPa}]}\end{array}$ & $\begin{array}{l}v \\
{[-]}\end{array}$ & $\begin{array}{l}\mu \\
{[-]}\end{array}$ & $\begin{array}{l}R_{m} \\
{[\mathrm{MPa}]}\end{array}$ & $\begin{array}{l}E / g \\
{\left[\frac{M P a}{m m}\right]}\end{array}$ \\
\hline XH500-4 & 4 & 0.5 & 151 & 0.35 & $0.5-0.6$ & 62 & 88 \\
H500 & 3.5 & 0.5 & 179 & 0.3 & $0.5-0.6$ & 70 & 150 \\
L750 & 2.2 & 0.75 & 250 & 0.26 & $0.5-0.6$ & 144 & 173 \\
M250 & 2.2 & 0.25 & 158 & 0.29 & $0.5-0.6$ & 57 & 232
\end{tabular}

perforation force for modified piercing punches by using Eq. 43:

$F_{P D i}=\beta \cdot F_{A \max }$

However, this model will be certain only for selected geometrical parameters of the piercing punches (like bowl depth and radius, shearing angle, and diameter). That is why this model will be developed in further research.

\section{Verification of the perforation force estimation model}

In order to verify the correctness of the proposed model, another group of belts which were not used for a model derivation was tested. Selected belts (XH500-4, H500, L750, and M250) have the same structure as the previously used ones, but its geometrical features and mechanical properties are different. Because authors wanted to check the belts that lie outside the range of model, which may give the highest possible errors, both very elastic and rigid belts were taken into consideration. For each type of the belt, the mechanical properties were determined using the methodology described in the paper and the results are presented in Table 11. Then the parameters necessary for a force estimation (compression area factor $\xi$ and strain at damage $\epsilon_{d m}$ ) were calculated based on the proposed models.

Table 12 Parameters needed for force estimation for the belts used for veryfication of the model

\begin{tabular}{llllllll}
\hline $\begin{array}{l}\text { Type } \\
\text { of belt }\end{array}$ & $\begin{array}{l}\xi_{\text {est }} \\
{[-]}\end{array}$ & $\begin{array}{l}\xi_{\text {cr }} \\
{[-]}\end{array}$ & $\begin{array}{l}\xi \\
{[-]}\end{array}$ & $\begin{array}{l}\epsilon_{d m} \\
{[-]}\end{array}$ & $\begin{array}{l}F_{\text {Emax }} \\
{[\mathrm{N}]}\end{array}$ & $\begin{array}{l}F_{\text {Amax }} \\
{[\mathrm{N}]}\end{array}$ & $\begin{array}{l}e_{A} \\
{[\%]}\end{array}$ \\
\hline XH500-4 & 0.2071 & 0.6 & 0.6 & 0.856 & 3541 & 3682 & 3.98 \\
H500 & 0.3678 & 0.65 & 0.65 & 0.824 & 3769 & 3715 & 1.43 \\
L750 & 1.0576 & 0.78 & 0.888 & 0.749 & 3944 & 3944 & 3.12 \\
M250 & 0.6159 & 0.78 & 0.78 & 0.92 & 2286 & 1964 & 14.09 \\
\hline
\end{tabular}

Table 13 Perforation forces and shape factors obtained from empirical tests

\begin{tabular}{lllllll}
\hline $\begin{array}{l}\text { Type } \\
\text { of belt }\end{array}$ & $\begin{array}{l}F_{P D C B} \\
{[\mathrm{~N}]}\end{array}$ & $\begin{array}{l}F_{P D D S} \\
{[\mathrm{~N}]}\end{array}$ & $\begin{array}{l}F_{P D S B} \\
{[\mathrm{~N}]}\end{array}$ & $\begin{array}{l}\beta_{P D C B} \\
{[-]}\end{array}$ & $\begin{array}{l}\beta_{P D D S} \\
{[-]}\end{array}$ & $\begin{array}{l}\beta_{P D S B} \\
{[-]}\end{array}$ \\
\hline XH500-4 & 1994 & 2226 & 1768 & 0.563 & 0.629 & 0.499 \\
H500 & 2257 & 2398 & 1532 & 0.599 & 0.636 & 0.406 \\
L750 & 2091 & 2127 & 1412 & 0.530 & 0.539 & 0.358 \\
M250 & 864 & 904 & 773 & 0.378 & 0.395 & 0.338 \\
\hline
\end{tabular}

As can be seen in Table 12, the selected belts, due to their extreme behaviour, have estimated $\xi$ factors whose values lie outside the range of model. That is why the critical values (either upper or lower) were used instead. The estimated perforation force along with the value obtained from the empirical tests and the percentage error of estimation are also presented in Table 12. The error does not exceed 15\% and for the majority of the specimen it was lower than $4 \%$. This implicates that the model proposed by the authors can be used to estimate the perforation force with high accuracy.

The second part of the model verification is connected with estimating the perforation force for modified piercing punches. In order to fulfill this assignment, empirical tests were performed, according to the methodology described in Section 4, and the peak values of the force along with the calculated shape factors are shown in Table 13. By using the estimated values of the force for a flat piercing punch and the model presented in Section 7, estimated peak forces and the shape factors $\beta$ were derived for three types of punches (PDCB, PDDS, PDCB) and shown in Table 14. By comparing the obtained results, we can deduce that the errors of force estimation for each shape of piercing punch equals respectively 29.3, 12.5, and $16 \%$. The higher inaccuracy is connected with the error cumulation at each stage of the estimation (using few different models). However, it is still possible to reduce the error by extending the analysis with the influence of the geometrical parameters of the piercing punch. Although the errors are rather high, the model can be still used to estimate the value of the force on the design stage of the punching

Table 14 Estimated values of the perforation force and shape factors

\begin{tabular}{lllllll}
\hline $\begin{array}{l}\text { Type } \\
\text { of belt }\end{array}$ & $\begin{array}{l}F_{P D C B} \\
{[\mathrm{~N}]}\end{array}$ & $\begin{array}{l}F_{P D D S} \\
{[\mathrm{~N}]}\end{array}$ & $\begin{array}{l}F_{P D S B} \\
{[\mathrm{~N}]}\end{array}$ & $\begin{array}{l}\beta_{P D C B} \\
{[-]}\end{array}$ & $\begin{array}{l}\beta_{P D D S} \\
{[-]}\end{array}$ & $\begin{array}{l}\beta_{P D S B} \\
{[-]}\end{array}$ \\
\hline XH500-4 & 1881 & 2504 & 1473 & 0.511 & 0.680 & 0.4 \\
H500 & 1775 & 2444 & 1486 & 0.478 & 0.658 & 0.4 \\
L750 & 1489 & 2186 & 1528 & 0.390 & 0.572 & 0.4 \\
M250 & 611 & 912 & 786 & 0.311 & 0.464 & 0.4 \\
\hline
\end{tabular}


dies for a specyfic type of belt, but proper safety factor should be considered.

\section{Conclusions}

Based on the presented research, the belt punching process is very complex and not a fully described issue. That is what makes the research important with regards to science and industry. The results shown in this paper prove that the perforation force can be reduced with the use of a proper punch profile. Based on the analysis, only three shapes of piercing punches (PDCB, PDDS, and PDSB) should be considered as a possible effective tool for composite belt punching, however in the current stage of research the spherical bowl punch gives the best combination of force reduction and hole precision. The derived shape factors along with the proposed analytical model make it possible to estimate the peak value of the perforation force with an inaccuracy between 4 and $15 \%$. The main advantage of this model is that to calculate the force, we need only basic mechanical properties of the belt, which can be obtained from a simple strength test or datasheets. This can be very helpful in a design process for the punching dies used for certain types of composites belts. Although combining this model with the FEM analysis has rather high inaccuracy especially at the beginning of the process, it still makes it useful for comparative analysis used in searching the effective geometry of the piercing punch due to the compatibility of the peak value of the perforation force. In further research the authors want to expand the model by reducing the assumptions and then analyzing the influence of the geometrical parameters (shear angles, bowl depth, and radius, punch diameter, etc.) of the punching tools on the perforation force.

Open Access This article is distributed under the terms of the Creative Commons Attribution 4.0 International License (http:// creativecommons.org/licenses/by/4.0/), which permits unrestricted use, distribution, and reproduction in any medium, provided you give appropriate credit to the original author(s) and the source, provide a link to the Creative Commons license, and indicate if changes were made.

Publisher's Note Springer Nature remains neutral with regard to jurisdictional claims in published maps and institutional affiliations.

\section{References}

1. Perneder R, Osborne I (2012) Handbook Timing beltsprinciples, calculations, applications. Springer, Berlin

2. Wojtkowiak D, Talaśka K, Malujda I, Domek G (2018) Analysis of the influence of the cutting edge geometry on parameters of the perforation process for conveyor and transmission belts. In: MATEC Web of Conferences, vol 157, p 01022
3. Wojtkowiak D, Talaśka K, Malujda I, Domek G (2017) Vacuum conveyor belts perforation-methods, materials and problems. Mechanik. https://doi.org/10.17814/mechanik.2017.12.192

4. Optbelt (2017) Technical manual polyurethane timing belts. http:// www.optibelt-usa.com. Accesed 31 January 2018

5. Marciniak Z (2002) Konstrukcja tocznikw. Ośrodek techniczny A.Marciniak, Warsaw

6. Suchy I (2006) Handbook of Die Design. McGraw-Hill Companies, New York

7. Quazi TZ, Shaikh RS (2012) An overview of clearance optimization in sheet metal blanking process. Int $\mathrm{J}$ Mod Eng Res (IJMER) 6(2):4547-4558

8. Kutuniva K, Karjalainen J, Mäntyjärvi K (2012) Effect of convex sheared punch geometry on cutting force of ultra-high-strength steel. Key Eng Mater 504-506:1359-1364

9. Bratus V, Kosel F, Kovac M (2010) Determination of optimal cutting edge geometry on the stamped orthotropic circular electrical steel sheet. J Mater Process Technol 210:396-407

10. Yamada T, Wang Z, Sasa T (2014) Effect of tool shape on galling behavior in plate shearing. Proceedia Eng 81:1817-1822

11. Groover MP (2010) Fundamentals of modern manufacturing materials, processes and systems Sheet metalworking, 4th. Wiley, New York, pp 443-482

12. Soares JA, Gipela ML, Lararin SF, Marcondes PVP (2013) Study of the punch-die clearance influence on the sheared edge quality of thick sheets. Int J Adv Manuf Technol 65:451-457

13. Uddeholm tooling, SSAB Swedish Steels (2016) Tooling solutions for advanced high strength steels-selection guidelines. www. uddeholm.com Accesed 31 January 2018

14. Uţuleanu S, Vlase A, Sindilă G, Căpăţănă N (2017) Study of the influence of punched contour geometry over the punch force using finite element analysis. MATEC Web of Conferences 112:1-6

15. Maiti SK, Ambekar AA, Singh UP, Date PP, Narasimhan K (2000) Assessment of influence of some process parameters on sheet metal blanking. J Mater Process Technol 1-3(102):249-256

16. Jadhav VJ, Shah BR (2017) Assessment \& Optimization of influence of some process parameters on sheet metal blanking. Int Res J Eng Technol 10(04):266-272

17. Nishad R, Totre A, Bodke S, Chauhan A (2013) An overview of the methodologies used in the optimization processes in sheet metal blanking. Int J Mech Eng Rob Res 2(2):307-314

18. Kulkarni D, AdhikraoShinde R, Prakash Badgujar J (2015) Clearance Optimization of Blanking Process. Int J Sci Eng Res 12(6):178-191

19. Zain MSM, Abdullah AB, Samad Z (2017) Effect of puncher profile on the precision of punched holes on composite panels. Int J Adv Manuf Technol 89:3331-3336

20. Chan HY, Abdullah AB, Samad Z (2015) Precision punching of hole on composite panels. Indian J Eng Mater Sci 22:641-651

21. Lambiase F, Durante M (2017) Mechanical behavior of punched holes produced on thin glass fiber reinforced plastic laminates. Compos Struct 173:25-34

22. Pramono AE, Indriyani R, Zulfia A, Subyakto (2015) Tensile and shear punch properties of bamboo fibers reinforced polymer composites. Int J Composite Mat 5:9-17

23. Karjalainen JA, Mäntyjärvi K, Juuso M (2007) Punching Force Reduction with Wave-Formed Tools. Key Eng Mater 344:209-216

24. Singh UP, Strepel AH, Kals HJJ (1992) Design study of the geometry of a punching/blanking tool. J Mater Process Technol 33:331-345

25. Yang T, Hao J, Liu G, Su HB, Chen XP, Qi YB (2014) Influence of punch shape on the fracture surface quality of hydropiercing holes. J Harbin Inst Technol 3(21):85-90

26. Yiemchaiyaphum S, Masahiko J, Thipprakmas S (2010) Die design in fine-piercing process by chamfering cutting edge. Key Eng Mater 413:219-224 
27. Thipprakmas S, Rojananan S, Paramaputi P (2008) An investigation of step taper-shaped punch in piercing process using finite element method. J Mater Process Technol 197:132-139

28. Liu W, Hao J, Liu G, Gao G, Yuan S (2016) Influence of punch shape on geometrical profile and quality of hole piercing-flanging under high pressure. Int J Adv Manuf Technol 86:1253-1262

29. Hanas WE (1972) Apparatus and method for fine blanking of parts. US3635067 Patent document. Jan. 18, 1972

30. Subramonian S, Altan T, Campbell C, Ciocirlan B (2013) Determination of forces in high speed blanking using FEM and experiments. J Mater Process Technol 213:2184-2190

31. Talaśka K, Wojtkowiak D (2018) Modelling a mechanical properties of the multilayer composite materials with the polyamide core. MATEC Web of Conferences 157:02052

32. Younes R, Hallal A, Fardoum F, Chehade FH (2012) Properties modeling for unidirectional composite materials. In: $\mathrm{Hu} \mathrm{N}$ (ed) Composite materials and their properties Intech, Rijeka, pp 391-408

33. Holmberg S, Persson K, Petersson H (1999) Nonlinear mechanical behaviour and analysis of wood and fibre materials. Comput Struct 72:459-480

34. Pal B, Haseebuddin MR (2012) Analytical estimation of elastic properties of polypropylene fiber matrix composite by finite element analysis. Adv Mat Phys and Chem 2:23-30

35. Case J, Chilver L, Ross C (1999) Lateral deflections of circular plates. In: Strength of Materials and Structures. Wiley, London, pp 458-491

36. Gujar PS, Ladhane KB (2015) Bending analysis of simply supported and clamped circular plate. SSRG Int J Civ Eng (SSRGIJCE) 5(2):69-75

37. Zyczkowski M (1981) Combined loadings in theory of plasticity. PWN, Warsaw, pp 35-39

38. Lubarda VA, Benson DJ, Meyers MA (2003) Strain-rate effects in rheological models inelastic response. Int J Plast 19:1097-1118

39. Marques SPC, Creus GJ (2012) Computational viscoelasticity, Springer, pp 13-15

40. Fleury E, Ha JS (1998) Small punch tests to estimate the mechanical properties of steels for steam power plant: I. Mechanical strength. Int J Press Vessel Pip 75:699-706
41. Bruchhausen M, Holmström S, Simonovski I, Austin T, Lapetite JM, Ripplinger S, de Hann F (2016) Recent developments in small punch testing: tensile properties and DBTT. Theor Appl Fract Mech 86:2-10

42. Singh J, Sharma NK, Sehgal SS (2017) Small punch testing: an alternative testing technique to evaluate tensile behavior of cortical bone. J Mech in Med and Biol 17:06

43. Amaral R, Teixeira P, Azinpour E, Santos AD, Cesar de Sa J (2016) Evaluation of ductile failure models in sheet metal forming. MATEC Web of Conferences 80:1-6

44. Dassault Systmes Simulia Corp (2013) Abaqus User's Manual: Version 6.13-2. http://abaqus.software.polimi.it/ Accesed 31 January 2018

45. Shetty N, Shahabaz SM, Sharma SS, Shetty SD (2017) A review on finite element method for machining of composite materials. Compos Struct 176:790-802

46. Dandekar CR, Shin YC (2012) Modeling of machining of composite materials: A review. Int J Mach Tools Manuf 57:102-121

47. Garcia JJ, Rangel C, Ghavami K (2012) Experiments with rings to determine the anisotropic elastic constants of bamboo. Constr Build Mater 31:52-57

48. Vasic S, Smith I, Landis E (2005) Finite element techniques and models for wood fracture mechanics. Wood Sci Technol 39: $3-17$

49. Torres LA, Ghavami K, Garcia JJ (2007) A transversely isotropic law for the determination of the circumferential young's modulus of bamboo with diametric compression tests. Lat Am Appl Res $37: 255-260$

50. Dandekar CR, Shin YC (2009) Multi-step 3D finite element modeling of subsurface damage in machining particulate reinforced metal matrix composites. Composites Part A 40(8):12311239

51. Zhou L, Huang ST, Wang D, Yu XL (2011) Finite element and experimental studies of the cutting process of $\mathrm{SiCp} / \mathrm{Al}$ composites with PCD tools. Int J Adv Manuf Technol 52:619_ 626 